Article

\title{
Pandora's Box-Influence of Contour Parameters on Roughness and Subsurface Residual Stresses in Laser Powder Bed Fusion of Ti-6Al-4V
}

\author{
Katia Artzt ${ }^{1, *}$, Tatiana Mishurova ${ }^{2}{ }^{\circledR}$, Peter-Philipp Bauer ${ }^{1}$, Joachim Gussone ${ }^{1}{ }^{\circledR}$, \\ Pere Barriobero-Vila ${ }^{1}$, Sergei Evsevleev ${ }^{2}$, Giovanni Bruno ${ }^{2,3}{ }^{\circledR}$, Guillermo Requena ${ }^{1,4}$ and \\ Jan Haubrich ${ }^{1}$ (1)
}

1 Institute of Materials Research, German Aerospace Center (DLR; Deutsches Zentrum für Luft-und Raumfahrt), Linder Höhe, 51147 Cologne, Germany; Peter-Philipp.Bauer@dlr.de (P.-P.B.); joachim.gussone@dlr.de (J.G.); pere.barrioberovila@dlr.de (P.B.-V.); guillermo.requena@dlr.de (G.R.); jan.haubrich@dlr.de (J.H.)

2 Bundesanstalt für Materialforschung und-Prüfung (BAM; Federal Institute for Materials Research and Testing), Unter den Eichen 87, 12205 Berlin, Germany; tatiana.mishurova@bam.de (T.M.); sergei.evsevleev@bam.de (S.E.); giovanni.bruno@bam.de (G.B.)

3 Institute of Physics and Astronomy, University of Potsdam, Karl-Liebknecht-Straße 24/25, 14476 Potsdam, Germany

4 Metallic Structures and Materials Systems for Aerospace Engineering, RWTH Aachen University, 52062 Aachen, Germany

* Correspondence: katia.artzt@dlr.de

Received: 29 June 2020; Accepted: 24 July 2020; Published: 28 July 2020

\begin{abstract}
The contour scan strategies in laser powder bed fusion (LPBF) of Ti-6Al-4V were studied at the coupon level. These scan strategies determined the surface qualities and subsurface residual stresses. The correlations to these properties were identified for an optimization of the LPBF processing. The surface roughness and the residual stresses in build direction were linked: combining high laser power and high scan velocities with at least two contour lines substantially reduced the surface roughness, expressed by the arithmetic mean height, from values as high as $30 \mu \mathrm{m}$ to $13 \mu \mathrm{m}$, while the residual stresses rose from $\sim 340$ to about $800 \mathrm{MPa}$. At this stress level, manufactured rocket fuel injector components evidenced macroscopic cracking. A scan strategy completing the contour region at $100 \mathrm{~W}$ and $1050 \mathrm{~mm} / \mathrm{s}$ is recommended as a compromise between residual stresses (625 MPa) and surface quality $(14.2 \mu \mathrm{m})$. The LPBF builds were monitored with an in-line twin-photodiode-based melt pool monitoring (MPM) system, which revealed a correlation between the intensity quotient $\mathrm{I}_{2} / \mathrm{I}_{1}$, the surface roughness, and the residual stresses. Thus, this MPM system can provide a predictive estimate of the surface quality of the samples and resulting residual stresses in the material generated during LPBF.
\end{abstract}

Keywords: Ti-6Al-4V; additive manufacturing; contour scan strategy; surface roughness; melt pool monitoring; residual stress; synchrotron X-ray diffraction

\section{Introduction}

Additive manufacturing (AM) technologies like directed energy deposition (DED) or laser powder bed fusion (LPBF) have been developed for the near-net-shape fabrication of metal components with high material efficiencies [1,2]. However, due to the nature of the processes and the used feedstocks (e.g., powders or wires), the obtainable geometric accuracies and surface qualities vary considerably [3] and are generally inferior to subtractive machining. 
The process parameters and processing strategies employed in LPBF determine the contour properties significantly. This is mostly due to powder particles remaining attached to the resolidified outer surfaces (i.e., secondary roughness), stair-case effects due to discrete layer-wise processing, the melt tracks, and, thus, the contour laser process itself (primary roughness or waviness) [4-7]. The surface roughness depends strongly on the build angle of the surface, e.g., a side, down- or up-skin surface $[5,8]$. This has a high impact on the fatigue properties of LPBF coupons or components $[4,7,9]$. In contrast, pores and defects in the bulk or even near-surface play a much smaller role for crack initiation and fatigue life [4]. Particularly, the combination of poor surface quality and high tensile stresses is reported to be critical in an as-built condition of LPBF Ti-6Al-4V, whereas in specimens with high compressive residual stresses (i.e., after hot isostatic pressing and subsequent shot-peening), a high surface roughness (of $R_{a} \leq 21 \mu \mathrm{m}$ ) plays a negligible role on crack initiation [8]. Leuders et al. concluded that "any improvement of surface roughness may greatly improve the cyclic properties" [8]. Since the primary roughness is one critical factor responsible for the degradation of the fatigue properties of LPBF Ti-6Al-4V [4], the optimization of the LPBF contour strategy and laser parameters is of major importance for the near-net-shape manufacturing of highly loaded components without expensive and time-consuming surface post-processing.

The scan strategies and laser parameters in LPBF also strongly influence the formation of residual stresses (RSs) [10-16]. The origins of the RS in AM are the steep and local thermal gradients developing during melting, remelting, reheating, solidification, and cool-down (see further Refs. [9,10,17]). The RSs in the as-built state prior to any heat treatment are generally sizable (up to $800 \mathrm{MPa}$ in Ti alloys) and may lead to detachment of support structures, cracking of parts, or geometrical distortion during manufacturing $[8,18,19]$. They are tensile in nature at the surface and in subsurface regions $[16,20]$ and are balanced by compressive stresses in the bulk of LPBF materials [21]. Therefore, every scan and laser parameter in LPBF, including those in the contour region, influences the thermal history of the part and the RS. Especially, different scan strategies have been studied by various research groups. While some reported rotating scan patterns achieved more homogeneous temperature distributions, which result in low RS [10,15], others concluded that stripe patterns alternating by $90^{\circ}$ minimized RS $[11,14]$.

The high tensile RS can be relieved by heat post-treatment (e.g., stress-relieving treatments; see Ref. [22] and therein) and even transformed to compressive stresses by post-processing by, e.g., laser or shot peening [8]. Generally, a stress relieve heat treatment of LPBF Ti-6Al-4V in a temperature range between 600 and $700{ }^{\circ} \mathrm{C}$ for times of ca. 2 to $3 \mathrm{~h}$ typically is sufficient to quantitatively eliminate the tensile stresses [22,23]. This is generally carried out prior to the removal of LPBF components from the build plates in order to avoid part distortion. Besides the reduction of RS, this thermal treatment promotes the decomposition of martensitic microstructures, which are present in the LPBF Ti-6Al-4V as-built conditions. This process leads to improved trade-offs between strength and ductility [24-26].

For advancing the technological maturity of metal AM, current research efforts focus also on process monitoring and quality control for fast and cost-effective solutions. With in situ monitoring systems, a better process understanding, higher reproducibility, and part quality might be achieved. In the long-term, a feedback-control system with a "self-optimization of the manufacturing process" [27] may be attainable. Several types of in situ monitoring systems for AM machines are already commercially available [28-31]. Most of these systems are based on optical methods [32-40], consisting of spatially resolved sensors (e.g., cameras) or spatially integrating sensors (i.e., pyrometers/photodiodes). An overview of melt pool monitoring (MPM) results is given, e.g., in [41-45].

Despite the growing number of experimental and simulation studies on the formation of residual stresses in LPBF of titanium alloys (e.g., [8,9,11-13,15-18,21]), the role of contour strategies for tackling subsurface residual stresses, as well as their interplay with the surface qualities, has received little attention so far. Hence, the present study was conducted to provide new insights for the optimization of contour scan strategies and contour laser parameters based on surface qualities and subsurface residual stress formation. Extensive use of the integrated melt pool monitoring tool developed by SLM Solutions $\mathrm{GmbH}$ was made for in situ process monitoring in order to study its potential as a tool 
to assess and estimate these properties prior to any part analysis. Besides proposing an optimized LPBF strategy for contour processing, a correlation between the intensity quotient $I_{2} / I_{1}$, the surface roughness, and the residual stresses was found, enabling a prediction of these properties from MPM already during a build. Surface roughness and the residual stresses were affected in an opposing manner by the contour parameters, requiring that any optimized or balanced contour scan strategy leads to a compromise between both properties.

\section{Materials and Methods}

\subsection{Sample Manufacturing}

All samples were manufactured with an SLM $280^{\mathrm{HL}}$ from SLM Solutions GmbH (Luebeck, Germany) with an integrated melt pool monitoring system. For the programming of the build job files, the software Magics (version 21.1, Materialise, Leuven, Belgium) and the SLM Solutions Metal build processor were used. The build platform was pre-heated to $200{ }^{\circ} \mathrm{C}$, and the LPBF process was carried out in inert argon gas (purity 5.0).

Plasma-atomized Ti-6Al-4V ELI grade 23 powder with a particle size of $d_{90}<50 \mu \mathrm{m}$ (AP\&C, Boisbriand Québec, Canada) was used. All specimens (dimensions $5 \times 5 \times 15 \mathrm{~mm}^{3}$ ) were built on $2 \mathrm{~mm}$ tall block supports (Figure 1). The specimens were systematically positioned close to each other (approx. $20 \mathrm{~mm}$ apart; Figure 1a) to reduce the influence of the specimens' placement on the base plate on the resulting material properties [13]. In order to ensure a more homogeneous powder recoating process, all samples were rotated by $20^{\circ}$ against the recoater direction. In the subsequent measurements, the same side surface on each specimen (marked in red in Figure 1a) was investigated to exclude side dependent effects [12].

(a)

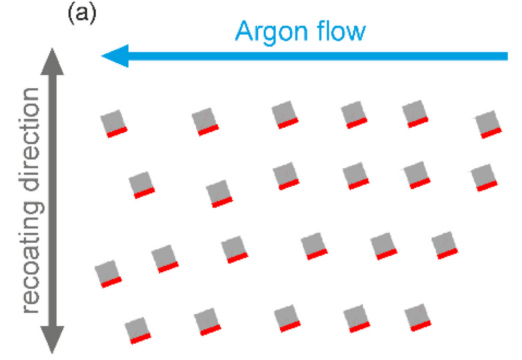

(b)

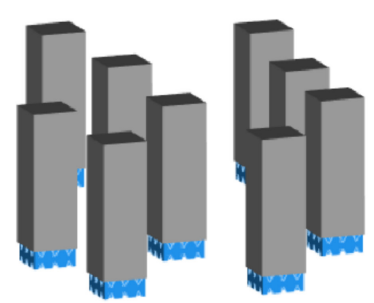

(c)

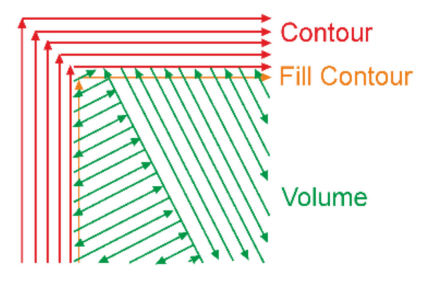

Figure 1. (a) Sample positions on the base plate; red marked are the sample sides, which were investigated in this study; (b) side view of the specimens $\left(5 \times 5 \times 15 \mathrm{~mm}^{3}\right)$, which were printed on 2 mm block supports; (c) example for a typical scan pattern used in this study consisting of 5 contour lines, 1 fill contour, and volume scan.

The details of the process parameters that were studied are listed in Appendix A.

For the sake of an easy comparison, the descriptor volume energy density $\mathrm{E}_{\mathrm{V}}$ has been used in this study with the laser power $\mathrm{P}$, the scanning velocity $\mathrm{v}$, the hatch distance $\mathrm{h}$, and the layer thickness $\mathrm{t}$ (Equation (1)).

$$
E_{\mathrm{v}}=\frac{P}{\mathrm{v} \cdot \mathrm{h} \cdot \mathrm{t}}
$$

A layer thickness of $t=30 \mu \mathrm{m}$ was chosen. For most of the specimens, two different parameter sets were used, one parameter set for the contour and fill contour and one for the volume (see example in Figure 1c). For the volume, a chess pattern with a minimum field size of $5 \mathrm{~mm}$ was used, which was rotated by $90^{\circ}$ from layer to layer. The same laser parameters were applied to the contour lines and to the fill contour. The only difference between these two types of the contour is that the fill contour lies within the area of the volume and, hence, this area is remelted during the scan. The fill contour is often used to reduce porosity in the transition area between the volume hatching vectors and the outer 
contour. In order to study the influence of contour process parameters, the process parameters, as well as the scan order, were varied. Examples of different scan patterns are depicted in Figure 2.

(a)
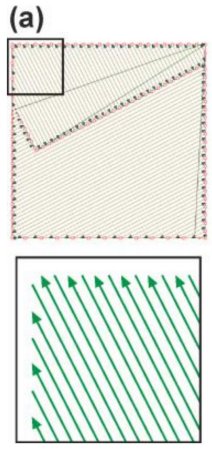

(b)
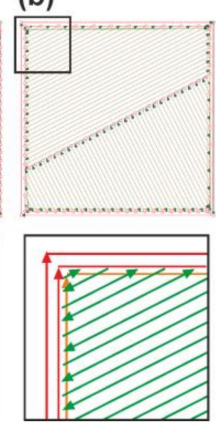

(c)
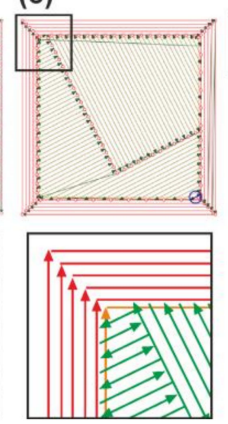

(d)

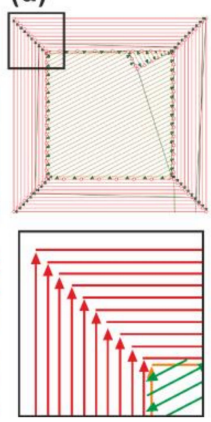

(e)

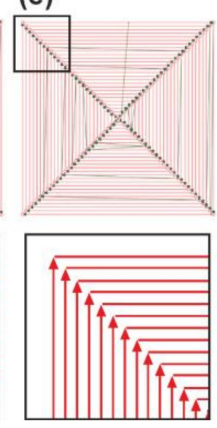

(f)
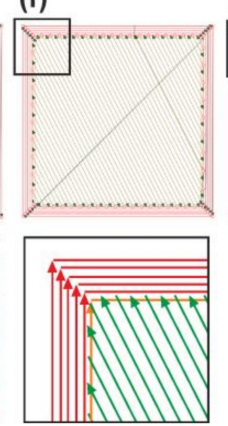

(g)

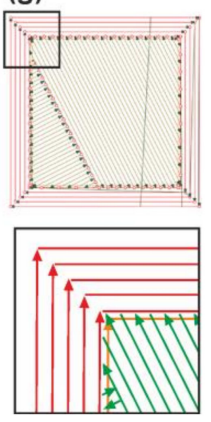

Figure 2. Examples for different scan patterns (bottom images represent enlargements of the top left corner in the upper sketches): (a) only chess pattern used (contour line with $\mathrm{P}=0 \mathrm{~W}$ ); (b) 2 contour lines $(\mathrm{h}=90 \mu \mathrm{m}) ;(\mathbf{c}) 5$ contour lines $(\mathrm{h}=90 \mu \mathrm{m})$, (d) 10 contour lines $(\mathrm{h}=90 \mu \mathrm{m}) ;(\mathbf{e})$ only contour lines $(\mathrm{h}=90 \mu \mathrm{m})$; (f) 5 contour lines with a small hatch distance of $\mathrm{h}=60 \mu \mathrm{m} ;(\mathrm{g}) 5$ contour lines with a large hatch distance of $\mathrm{h}=120 \mu \mathrm{m}$.

After manufacturing, the specimens were removed carefully from the build plate without influencing the residual stress state. Finally, the excess powder was removed ultrasonically.

For comparison, a selected post-processing treatment was conducted for one of the specimens: The specimen was first grit-blasted (4 bar) and afterward shot-peened for 1 min with Zirshot 210 (Carlo Bernasconi AG, Bern, Switzerland) at 6 bar (sample distance: 50-60 mm).

\subsection{Melt Pool Monitoring}

The SLM $280^{\mathrm{HL}}$ machine used in this study is equipped with a commercial optical melt pool monitoring (MPM) system from SLM Solutions GmbH (Luebeck, Germany), consisting of two photodiodes in the near-infrared [46-48]. The emitted thermal radiation is acquired by both photodiodes and recorded in layer-wise fashion as values $\mathrm{I}_{1}$ and $\mathrm{I}_{2}$ dependent on the current laser scanner coordinates. An example of $\mathrm{I}_{1}$ for a typical cuboid sample layer is depicted in Figure 3.

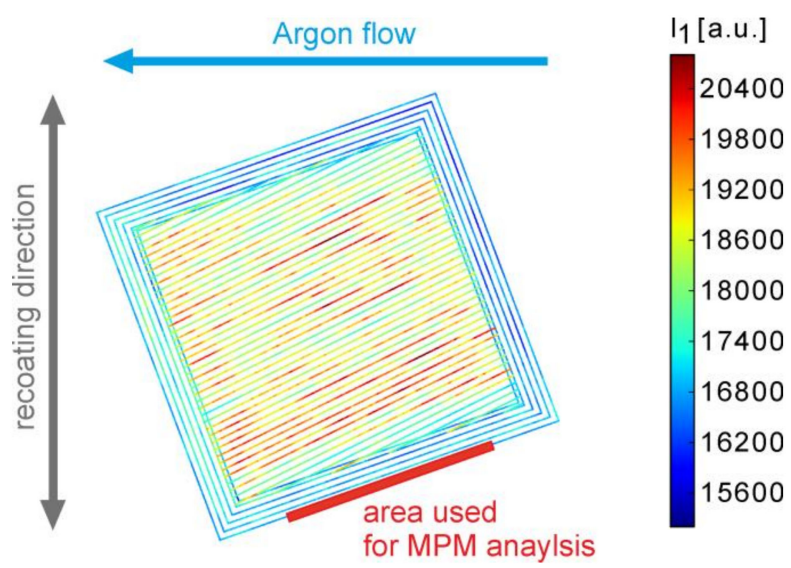

Figure 3. MPM (melt pool monitoring) photodiode intensity $\mathrm{I}_{1}$ for one layer of sample \#05 (LPBF (laser powder bed fusion) parameters: 5 contour lines with a contour laser power $\mathrm{P}_{\mathrm{cl}}=100 \mathrm{~W}$, contour velocity $\mathrm{v}_{\mathrm{cl}}=525 \mathrm{~mm} / \mathrm{s}$; volume laser power $\mathrm{P}=175 \mathrm{~W}$, velocity $\mathrm{v}=500 \mathrm{~mm} / \mathrm{s}$, see Appendix $\mathrm{A}$, Table A1). The data of the outer contour line within the red marked area was used for a consecutive comparison to roughness and stress results. 
The roughness and residual stress measurements were analyzed in the context of the MPM responses. Hence, the mean values and the standard deviations of the intensities $I_{1}$ and $I_{2}$, as well as the quotient $\mathrm{I}_{2} / \mathrm{I}_{1}$, were calculated from a similar region of each sample and along the building direction (marked in red in Figure 3). Both $\mathrm{I}_{1}$ and $\mathrm{I}_{2}$, as well as $\mathrm{I}_{2} / \mathrm{I}_{1}$, are presented below because $\mathrm{I}_{1}$ and $\mathrm{I}_{2}$ showed only qualitatively roughly similar trends, leading to a non-constant quotient. The data were filtered according to the following rules:

(i) only data points near the surface were considered from the selected region extending inwards $50 \mu \mathrm{m}$ from the sample border;

(ii) only the middle part of the contour line was selected to exclude possible inhomogeneity towards the start or end of a specific scan vector. An offset of $1 \mathrm{~mm}$ towards the corners was chosen;

(iii) layers from a build height between 4 and $11 \mathrm{~mm}$ were evaluated;

(iv) for data reduction only, each fifth measurement value (i.e., one value each $50 \mu$ s) was considered.

Using these filtering rules, between 150 and 970 data points were obtained per layer depending on the chosen scanning velocity. In total, 233 layers were evaluated, meaning that at least 35,000 values were analyzed for each specimen.

\subsection{Roughness Measurements}

A confocal ZEISS LSM 700 laser scanning microscope (LSM), with an EC Epiplan-Apochromat 10x/0.3 HD DIC M27 (100× magnification) objective from Zeiss AG, Oberkochen, Germany, was used for roughness characterization. The same sample surface used for the MPM analysis (see Figure 3) and the residual strain measurements were characterized. A section in the middle of the cuboid's side surface with a size of $1.75 \times 1.75 \mathrm{~mm}^{2}$ was chosen with a lateral resolution of $1.25 \mu \mathrm{m}(3 \times 3$ tiles with an overlap of 10\%). Images from 90-100 different heights were taken for each sample, which corresponded to a resolution in the height of around $2.25-2.3 \mu \mathrm{m}$. The smallest available pinhole, a unidirectional scan direction, a digital gain of around 200, a medium laser power, and the second-highest scan speed were used. The measurement time amounted to around $30 \mathrm{~min}$ per specimen. Two different roughness properties - the arithmetic mean height $S_{a}$ and the maximum height $S_{z}$-were calculated according to DIN EN ISO 25178-2:2012-09 [49] using the ConfoMap 7 (ZEISS AG, Oberkochen, Germany) software. Representative LSM images are shown in Supplementary Figure S2.

\subsection{Synchrotron X-ray Diffraction}

Energy-dispersive diffraction experiments were conducted at the EDDI beamline of the synchrotron source BESSY II (Helmholtz Zentrum Berlin, Germany) [50]. The beamline exhibited a white beam (energy range 10-150 keV), which could be used to generate diffractograms dependent on the energy at a constant diffraction angle $\theta$. The peak energy $\mathrm{E}_{\mathrm{hkl}}$ (in keV) of the different crystallographic planes $\{\mathrm{hkl}\}$ was directly correlated to the corresponding lattice spacing $\mathrm{d}_{\mathrm{hkl}}$ :

$$
\mathrm{d}_{\mathrm{hkl}}(A)=\frac{6.199}{\sin \theta} \frac{1}{\mathrm{E}_{\mathrm{hkl}}}
$$

Several peak positions were obtained in each measurement that could be attributed to different penetration depths $\tau$ [51], depending on the linear absorption coefficient $\mu\left(E_{h k l}\right)$ at the energy $E_{h k l}[50]$ :

$$
\tau=\frac{\sin \theta}{2 \mu\left(E_{h k l}\right)} \cos \psi
$$

The chosen setup was identical to the one used in previous measurements $[12,13,16]$. All measurements were conducted in reflection at a diffraction angle of $2 \theta=8^{\circ}$. With primary and secondary slit dimensions of $500 \mu \mathrm{m} \times 500 \mu \mathrm{m}$ and $30 \mu \mathrm{m}$ (vertical opening), respectively, a gauge volume length of $3.8 \mathrm{~mm}$ resulted (Figure 4; see further Ref. [20]). The residual stresses (RSs) were 
calculated with the $\sin ^{2} \psi$ method [52]. Importantly for the application of this method, (i) random crystallographic textures and (ii) negligible residual stresses (RSs) in the surface normal direction ( $\sigma_{\mathrm{yy}}$ $\approx 0 \mathrm{MPa}$, i.e., a planar stress state) have to be assumed. Because experimentally obtained diffraction elastic constants were not available for as-built LPBF Ti-6Al-4V, diffraction elastic constants for $\alpha$-Ti calculated according to the Eshelby-Kröner model and reported in [16] were used.

(a)

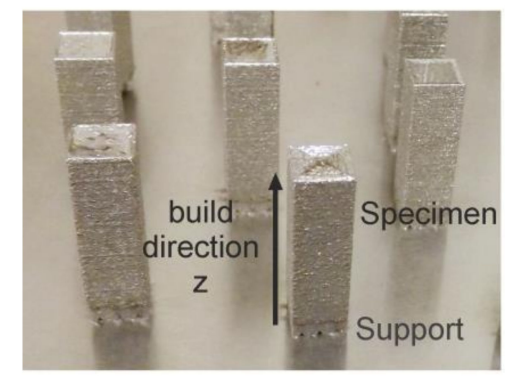

(b)

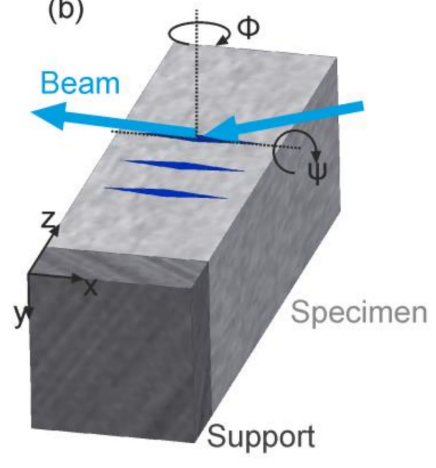

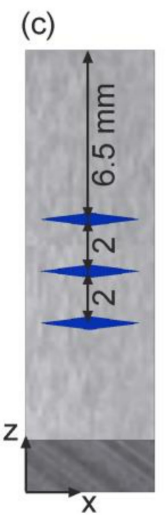

Figure 4. (a) Image of specimens on the base plate (specimen size $5 \times 5 \times 15 \mathrm{~mm}^{3}+2 \mathrm{~mm}$ support); $(\mathbf{b}, \mathbf{c})$ simplified gauge volume shape and measurement points for measurement of strains in build direction $\mathrm{z}\left(\phi=0^{\circ}\right)$. The identical sample sides were analyzed with MPM and diffraction (see Figure 1).

Residual stresses were investigated near the surface of small cuboids $\left(5 \times 5 \times 15 \mathrm{~mm}^{3}\right)$, as in previous studies $[12,13]$. Contrary to those studies, the surface plane (position $y=0$ ) for the alignment of samples was defined by means of the integrated diffraction intensities instead of using a laser system. This was done because of the high roughness of the samples that can lead to erroneous positioning and, thus, erroneous determination of RS at the surface [13]. Integrated diffraction intensities near zero are obtained if the gauge volume is outside of the sample, whereas maximal intensities imply that the gauge volume is completely inside. Therefore, the y-position corresponding to half of the maximal intensity was defined as "surface" and set to be $y=0$. This procedure was repeated for each measuring point and for each strain direction component ( $x$ and $z$ ).

In the previous studies, subsurface RSs were measured at 7 different points along one side of each sample (Figure 1a) $[12,13]$. Near the top of the specimens, stresses were low and increased towards the bottom until a stress plateau was reached at distances $\geq 6.5 \mathrm{~mm}$. In order to use the measurement time effectively, only 3 positions within this stress plateau were measured (at $6.5 \mathrm{~mm}, 8.5 \mathrm{~mm}$, and $10.5 \mathrm{~mm}$ from the top, see Figure $4 \mathrm{c}$ ), and the average RS values were calculated in build direction $\sigma_{\mathrm{zz}}$ and perpendicular to it $\sigma_{\mathrm{xx}}$.

Further details regarding the choice of the $\{103\}$-reflection, the determination of the surface level, and the selection of the gauge depth for the RS are provided in the Supplementary.

Since only $\sigma_{\mathrm{zz}}$ was considered for analysis and discussion, the $\sigma_{\mathrm{xx}}$ values are only given in Supplementary Materials Table S1. Importantly, no correlation between $\sigma_{\mathrm{xx}}$ and $\sigma_{\mathrm{zz}}$ was evident (see Supplementary Figure S3).

The number of measured specimens was limited due to the available beamtime at the synchrotron facility. However, for future studies, the investigation of a larger number of specimens for further statistical analysis would be desired. This would enable characterizing for, e.g., the effects of control factors (see Ref. [53]). 


\section{Results}

\subsection{Effect of the Scan Pattern}

Commonly, LPBF manufacturing is carried out with two different parameter sets-one set for the outer contour region, and one set for the volume of the part or specimen. However, in order to investigate the effect of the scan pattern, here, only one parameter set was used per sample (Table 1; for the sake of simplicity, all specimens are listed in Appendix A, Table A1). Specimens \#01 and \#02 were printed with only contour lines (CL) from the outside to the inside (O-I) and starting from the inside and finishing with the outside (I-O), respectively. Specimens \#03 and \#04 were printed only with volume hatching but using different laser parameters.

Table 1. Samples built with a single scan strategy of different scan patterns consisting either of contour or volume scan vectors.

\begin{tabular}{|c|c|c|c|c|c|c|c|c|c|c|c|}
\hline \multirow[b]{2}{*}{ No } & \multirow[b]{2}{*}{$\begin{array}{l}\text { Scan } \\
\text { Order }\end{array}$} & \multirow[b]{2}{*}{$\begin{array}{l}\text { Scan } \\
\text { Strategy } \\
\text { Contour }\end{array}$} & \multirow[b]{2}{*}{$\begin{array}{c}\text { Scan } \\
\text { Strategy } \\
\text { Volume }\end{array}$} & \multicolumn{4}{|c|}{ Contour Parameters } & \multicolumn{4}{|c|}{ Volume Parameters } \\
\hline & & & & $\begin{array}{c}\text { Power } \\
\text { P }_{C L} \\
\text { (W) }\end{array}$ & $\begin{array}{c}\text { Scan vel. } \\
\mathbf{v}_{\mathrm{CL}} \\
(\mathrm{mm} / \mathrm{s})\end{array}$ & $\begin{array}{l}\text { Hatch } \\
\mathrm{h}_{\mathrm{CL}} \\
(\mu \mathrm{m})\end{array}$ & $\begin{array}{c}E_{\mathrm{v}, \mathrm{cl}} \\
\left(\mathrm{J} / \mathrm{mm}^{3}\right)\end{array}$ & $\begin{array}{l}\text { Power } \\
\text { P (W) }\end{array}$ & $\begin{array}{c}\text { Scan vel. } \\
\mathbf{v} \\
(\mathrm{mm} / \mathrm{s})\end{array}$ & $\begin{array}{c}\text { Hatch } \\
\text { H } \\
(\mu \mathrm{m})\end{array}$ & $\begin{array}{c}E_{V} \\
\left(J / \mathrm{mm}^{3}\right)\end{array}$ \\
\hline$\# 01$ & - & CL O-I & - & 100 & 525 & 90 & 71 & - & - & - & - \\
\hline \#02 & - & CL I-O & - & 100 & 525 & 90 & 71 & - & - & - & - \\
\hline$\# 03$ & - & - & $\begin{array}{l}\text { Chess } \\
\text { (cs100) }\end{array}$ & - & - & - & - & 100 & 525 & 90 & 71 \\
\hline$\# 04$ & - & - & $\begin{array}{l}\text { Chess } \\
\text { (cs175) }\end{array}$ & - & - & - & - & 175 & 500 & 100 & 117 \\
\hline
\end{tabular}

The particular laser parameters for the contour $(\# 01, \# 02)$ were derived from the standard SLM Solutions contour strategy used for Ti-6Al-4V (i.e., for the contour: CL O-I). The parameters for the volume regions (\#04) were based on the recent process window optimization presented in [54]. For sample \#03, the contour parameters were adapted to the volume hatching for comparison.

$P$ refers to the laser power, $v$ to the scan velocity and $h$ to the hatch distance used in the volume $(\mathrm{V})$, or the contour region $(\mathrm{CL})$, respectively. $\mathrm{E}_{\mathrm{V}}$ corresponds to the volume energy density of the parameter set.

The MPM signals $I_{1}, I_{2}$, and $I_{2} / I_{1}$ were influenced mostly by the laser power P (Figure 5a): The samples produced with the same volume energy density $E_{v}$ (\#01-\#03) showed lower MPM intensities than the sample with higher $\mathrm{E}_{\mathrm{V}}(\# 04)$. The effects of changing scan strategies, in contrast, were much weaker in the MPM. When the scan order of the contour lines was inside to outside (i.e., \#02; CL I-O), only slightly higher $\mathrm{I}_{1}$ and $\mathrm{I}_{2}$ responses were obtained compared to the reverse sequence. In the case of printing the outer contour line last (CL I-O), the inner volume had already been molten and would still be hot. As a result, the heat loss caused by heat conduction to the surrounding material would be smaller for the last contour line, possibly leading to slightly higher melt pool temperatures and thermal emissions. The photodiodes would not only acquire photons emitted from the melt pool but also from the hot surrounding material. Both factors would contribute to the higher MPM intensities for \#02 compared to \#01.

For samples \#03 and \#4, produced only with volume hatching using the chess pattern and different laser powers, mainly the high standard deviations in the MPM data stood out. This was likely caused by scan lines that start or end in the detection area since usually more unstable and varying melt conditions prevail at the terminal points of the scan vectors.

For the surface roughness (Figure $5 b$ ), the role of the scan patterns was more important than $E_{V}$. Smaller surface roughness is generally obtained when contour lines are used [6]. In this case, the use of contour lines reduced the arithmetic mean roughness $S_{a}$ by a factor of $\sim 2$.

The influence of the scan pattern on the residual stresses (Figure $5 c$ ) depended on the stress component. For the residual stresses $\sigma_{\mathrm{zz}}$ in build direction, $\mathrm{E}_{\mathrm{V}}$ dominated the effects: higher $\sigma_{\mathrm{zz}}$ values 
were measured for samples produced at lower volume energy densities (\#01-\#03). This was consistent with previous studies $[12,13,16]$.

(a)

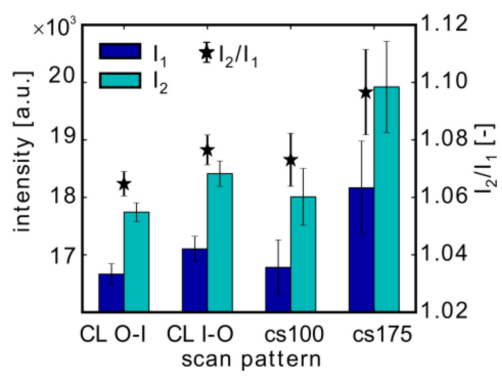

(b)

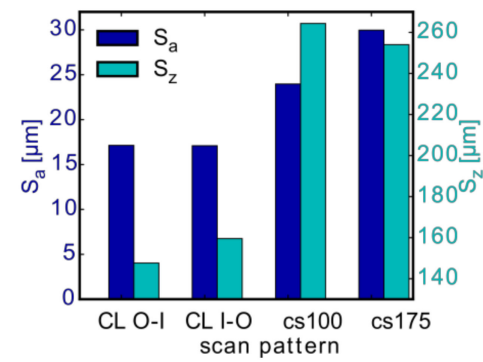

(c)

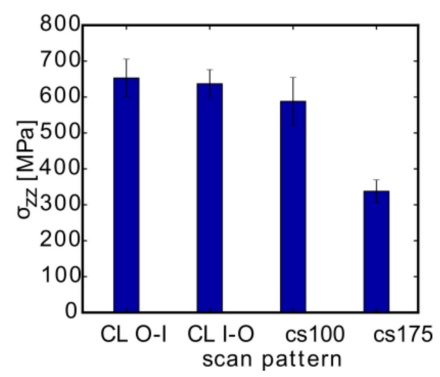

Figure 5. Influence of the scan pattern on the MPM data (a), on the surface roughness (b), and on the residual stresses (c). Depicted results are from samples \#01 (CL O-I), \#02 (CL I-O), \#03 (chess scan strategy with $\mathrm{P}=100 \mathrm{~W}$ ), and \#04 (chess/P = $175 \mathrm{~W}$ ). CL O-I, contour lines from the outside to the inside; CL I-O, contour lines from the inside and finishing with the outside.

\subsection{Effect of the Scan Order}

Samples \#05 to \#08 were printed in order to analyze the role of the scan order of the volume (V) and contour lines (CL). The volume process parameters were fixed at $\mathrm{P}=175 \mathrm{~W}, \mathrm{v}=500 \mathrm{~mm} / \mathrm{s}$, and $\mathrm{h}=100 \mu \mathrm{m}$. The contour consisted of five contour lines and one fill contour line, all of which were printed with $\mathrm{P}_{\mathrm{CL}}=100 \mathrm{~W}, \mathrm{v}_{\mathrm{CL}}=525 \mathrm{~mm} / \mathrm{s}$, and $\mathrm{h}_{\mathrm{CL}}=90 \mu \mathrm{m}$.

The following samples with their particular scan sequences were investigated (Table 2):

Table 2. Samples build with different scan orders.

\begin{tabular}{|c|c|c|c|c|c|c|c|c|c|c|c|}
\hline \multirow[b]{2}{*}{ No } & \multirow[b]{2}{*}{$\begin{array}{l}\text { Scan } \\
\text { Order }\end{array}$} & \multirow[b]{2}{*}{$\begin{array}{l}\text { Scan Strategy } \\
\text { Contour/\# of } \\
\text { Contour Lines }\end{array}$} & \multirow[b]{2}{*}{$\begin{array}{l}\text { Scan } \\
\text { Strategy } \\
\text { Volume }\end{array}$} & \multicolumn{4}{|c|}{ Contour Parameters } & \multicolumn{4}{|c|}{ Volume Parameters } \\
\hline & & & & $\begin{array}{l}\text { Power } \\
\text { P }_{C L} \\
(W)\end{array}$ & $\begin{array}{c}\text { Scan vel. } \\
v_{\mathrm{CL}} \\
(\mathrm{mm} / \mathrm{s})\end{array}$ & $\begin{array}{l}\text { Hatch } \\
\mathrm{h}_{\mathrm{CL}} \\
(\mu \mathrm{m})\end{array}$ & $\begin{array}{c}E_{\mathrm{v}, \mathrm{cl}} \\
\left(\mathrm{J} / \mathrm{mm}^{3}\right)\end{array}$ & $\begin{array}{l}\text { Power } \\
\text { P (W) }\end{array}$ & $\begin{array}{l}\text { Scan vel. } \\
\text { v (mm/s) }\end{array}$ & $\begin{array}{l}\text { Hatch } \\
\mathrm{h}(\mu \mathrm{m})\end{array}$ & $\begin{array}{c}E_{V} \\
\left(J / \mathrm{mm}^{3}\right)\end{array}$ \\
\hline \#05 & CL-V & & & & & & & & & & \\
\hline $\begin{array}{l}\# 06 \\
\# 0\end{array}$ & CL-V & CL $(\mathrm{O}-\mathrm{I}) / 5$ & Chess & 100 & 525 & 90 & 71 & 175 & 500 & 100 & 117 \\
\hline $\begin{array}{l}\# 07 \\
\# 08\end{array}$ & $\begin{array}{l}\text { V-CL } \\
\text { V-CL }\end{array}$ & & & & & & & & & & \\
\hline
\end{tabular}

$\mathrm{P}$ refers to the laser power, $\mathrm{v}$ to the scan velocity and $\mathrm{h}$ to the hatch distance used in the volume $(\mathrm{V})$, or the contour region $(\mathrm{CL})$, respectively. $\mathrm{E}_{\mathrm{V}}$ corresponds to the volume energy density of the parameter set.

Again, the recorded MPM intensities $\mathrm{I}_{1}$ and $\mathrm{I}_{2}$ were slightly higher in case of scanning the contour lines from the inside to the outside (Figure 6a; samples \#06 (CL (I-O)-V) and \#07 (V-CL (I-O)).

(a)

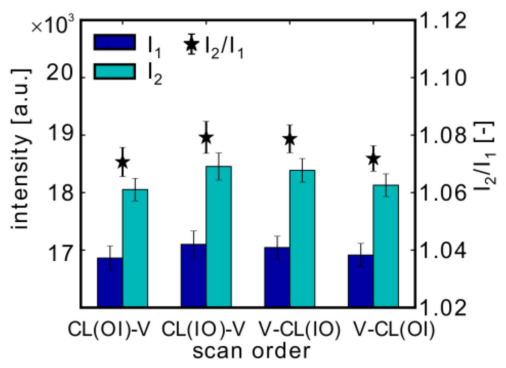

(b)

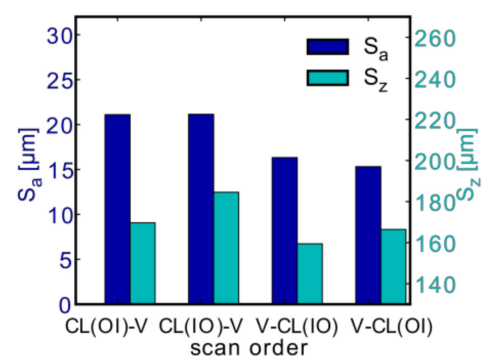

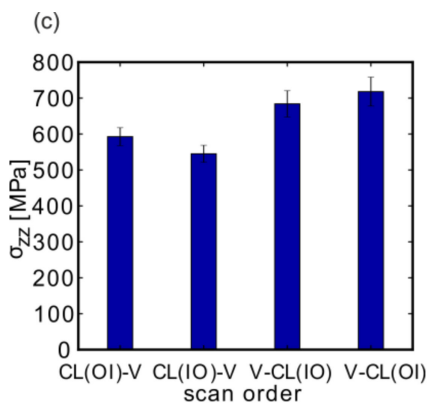

Figure 6. Influence of the scan order on the MPM data (a), on the surface roughness (b), and on the residual stresses (c). Depicted are the results from samples \#05 (CL(O-I)-V), \#06 (CL(I-O)-V), \#07 (V-CL(I-O)), and \#08 (V-CL(O-I)). 
The surface roughness $S_{a}$ and $S_{z}$ (Figure $6 b$ ) was slightly reduced when the inner volume was scanned before the outer contour vectors. In accordance with the results from the scan pattern variations \#01 (CL (O-I) and \#02: CL (I-O)), the scan order of the contour lines seemed to be less relevant for the studied coupons.

A contrary effect was observed for the residual stresses in the build direction (Figure $6 c$ ): $\sigma_{\mathrm{zz}}$ was slightly higher when either the volume was scanned first or when the scan order of the contour lines was "outside to inside".

\subsection{Effect of the Number of Contour Lines}

In the standard SLM Solutions scan strategy for Ti-6Al-4V, two contour lines were used (i.e., CL O-I, followed by volume hatching, \#09) (Standard SLM Solutions scan strategy for Titanium in Metal Build Processor 2.1, setting Ti_SLM_BP2.1_30_Stripes-US_T200_S21-01_V5002). In order to investigate their influence, the contour vectors were increased from 2 (sample \#09) to 5 (\#05) and 10 (\#10). The same volume process parameters $(\mathrm{P}=175 \mathrm{~W} ; \mathrm{v}=500 \mathrm{~mm} / \mathrm{s} ; \mathrm{h}=100 \mu \mathrm{m})$ and the same contour parameters $\left(\mathrm{P}_{\mathrm{CL}}=100 \mathrm{~W} ; \mathrm{v}_{\mathrm{CL}}=525 \mathrm{~mm} / \mathrm{s} ; \mathrm{h}_{\mathrm{CL}}=90 \mu \mathrm{m}\right.$ ) were chosen (Table 3 ). The scan order for the contour lines was "outside to inside" (before volume) for all specimens. These specimens could be compared to those manufactured either without contour lines (only volume hatching; \#04) or the one printed merely with contour vectors (\#01).

Table 3. Samples used to compare different contour line counts.

\begin{tabular}{|c|c|c|c|c|c|c|c|c|c|c|c|}
\hline \multirow[b]{2}{*}{ No } & \multirow[b]{2}{*}{$\begin{array}{l}\text { Scan } \\
\text { Order }\end{array}$} & \multirow[b]{2}{*}{$\begin{array}{c}\text { Scan Strategy } \\
\text { Contour/\# of } \\
\text { Contour Lines }\end{array}$} & \multirow[b]{2}{*}{$\begin{array}{c}\text { Scan } \\
\text { Strategy } \\
\text { Volume }\end{array}$} & \multicolumn{4}{|c|}{ Contour Parameters } & \multicolumn{4}{|c|}{ Volume Parameters } \\
\hline & & & & $\begin{array}{l}\text { Power } \\
P_{C L} \\
\text { (W) }\end{array}$ & $\begin{array}{c}\text { Scan vel. } \\
\mathbf{v}_{\mathrm{CL}} \\
(\mathrm{mm} / \mathrm{s})\end{array}$ & $\begin{array}{l}\text { Hatch } \\
\mathrm{h}_{\mathrm{CL}} \\
(\mu \mathrm{m})\end{array}$ & $\begin{array}{c}\mathrm{E}_{\mathrm{v}, \mathrm{cl}} \\
\left(\mathrm{J} / \mathrm{mm}^{3}\right)\end{array}$ & $\begin{array}{l}\text { Power } \\
\mathbf{P} \\
\text { (W) }\end{array}$ & $\begin{array}{l}\text { Scan vel. } \\
\mathrm{v}(\mathrm{mm} / \mathrm{s})\end{array}$ & $\begin{array}{l}\text { Hatch } \\
\text { h } \\
(\mu \mathrm{m})\end{array}$ & $\begin{array}{c}E_{v} \\
\left(J / \mathrm{mm}^{3}\right)\end{array}$ \\
\hline$\# 04$ & $\mathrm{~V}$ & $\overline{0}$ & Chess & - & - & - & - & 175 & 500 & 100 & \\
\hline \#09 & CL-V & $\begin{array}{c}\mathrm{CL}(\mathrm{O}-\mathrm{I}) \\
2\end{array}$ & Chess & 100 & 525 & 90 & 71 & 175 & 500 & 100 & 117 \\
\hline \#05 & CL-V & $\begin{array}{c}\mathrm{CL}(\mathrm{O}-\mathrm{I}) \\
5\end{array}$ & Chess & 100 & 525 & 90 & 71 & 175 & 500 & 100 & 117 \\
\hline$\# 10$ & CL-V & $\begin{array}{c}\mathrm{CL}(\mathrm{O}-\mathrm{I}) \\
10\end{array}$ & Chess & 100 & 525 & 90 & 71 & 175 & 500 & 100 & 117 \\
\hline$\# 01$ & $\mathrm{CL}$ & $\begin{array}{c}\mathrm{CL}(\mathrm{O}-\mathrm{I}) \\
\infty\end{array}$ & - & 100 & 525 & 90 & 71 & - & - & - & - \\
\hline
\end{tabular}

The MPM signals, as well as the roughness, showed similar trends with the highest values obtained in the case of pure volume hatching (Figure 7a). Consistent with the observations in Section 3.1, the higher $\mathrm{E}_{\mathrm{v}}$ of the volume hatching versus the contour parameters was mainly responsible for the higher MPM intensities when no contour vectors were used.

The higher roughness was related to the scan pattern, i.e., numerous scan vectors ending or starting on the sample edge causing higher $S_{a}$ values than scan vectors paralleling the sample edge (Figure $7 \mathrm{~b}$ ). Thus, when contour lines were used, the MPM intensities and the roughness decreased substantially. The chosen number of contour lines appeared to be secondary. Because the outermost contour line was scanned first, the rest of the scan pattern on the inside became less relevant, at least for MPM and the surface quality.

However, the number of contour lines strongly affected the residual stresses (Figure $7 \mathrm{c}$ ). The $\sigma_{\mathrm{zz}}$ component seemed to converge on a plateau value for more than 10 contour lines. Most of the increase of the residual stress component $\sigma_{\mathrm{zz}}$ was obtained with the first five contour lines used. 
(a)

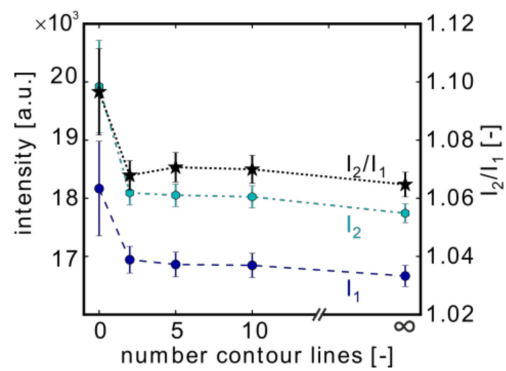

(b)

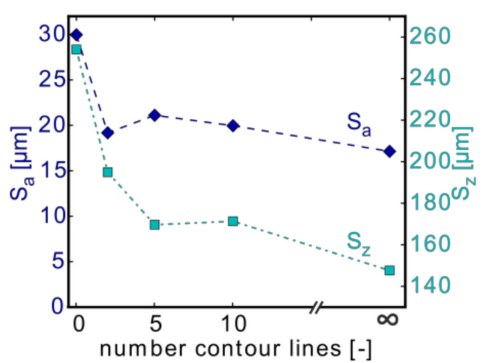

(c)

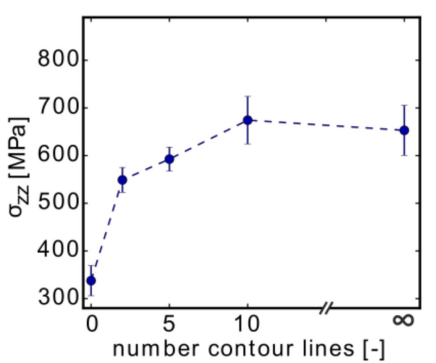

Figure 7. The influence of the contour line count on the MPM data (a), on the surface roughness (b), and on the residual stresses (c). Depicted are the results from samples \#04 (only volume, no contour lines), \#09 (2 contour lines), \#05 (5 contour lines), \#10 (10 contour lines), and \#01 (only contour lines, no volume). Note: The lines connecting the measurement points are only provided as a guide for the eye.

\subsection{Variation of Main Laser Parameters}

The contour laser power $\mathrm{P}_{\mathrm{CL}}$, scan velocity $\mathrm{v}_{\mathrm{CL}}$, and the hatch distance $\mathrm{h}_{\mathrm{CL}}$ were varied in the next step (Table 4). The number of contour lines and the volume parameters were kept constant.

Table 4. Varying the main laser parameters, $\mathrm{E}_{\mathrm{V}}=$ variable.

\begin{tabular}{|c|c|c|c|c|c|c|c|c|c|c|c|}
\hline \multirow[b]{2}{*}{ No } & \multirow[b]{2}{*}{$\begin{array}{l}\text { Scan } \\
\text { Order }\end{array}$} & \multirow[b]{2}{*}{$\begin{array}{c}\text { Scan Strategy } \\
\text { Contour/\# of } \\
\text { Contour Lines }\end{array}$} & \multirow[b]{2}{*}{$\begin{array}{l}\text { Scan } \\
\text { Strategy } \\
\text { Volume }\end{array}$} & \multicolumn{4}{|c|}{ Contour Parameters } & \multicolumn{4}{|c|}{ Volume Parameters } \\
\hline & & & & $\begin{array}{c}\text { Power } \\
\text { P }_{C L} \\
\text { (W) }\end{array}$ & $\begin{array}{c}\text { Scan vel. } \\
v_{\mathrm{CL}} \\
(\mathrm{mm} / \mathrm{s})\end{array}$ & $\begin{array}{c}\text { Hatch } \\
\mathrm{h}_{\mathrm{CL}} \\
(\mu \mathrm{m})\end{array}$ & $\begin{array}{c}E_{\mathrm{v}, \mathrm{cl}} \\
\left(\mathrm{J} / \mathrm{mm}^{3}\right)\end{array}$ & $\begin{array}{c}\text { Power } \\
\text { P } \\
\text { (W) }\end{array}$ & $\begin{array}{l}\text { Scan vel. } \\
\text { v (mm/s) }\end{array}$ & $\begin{array}{c}\text { Hatch } \\
\text { H } \\
(\mu \mathrm{m})\end{array}$ & $\begin{array}{c}E_{v} \\
\left(\mathrm{~J} / \mathrm{mm}^{3}\right)\end{array}$ \\
\hline$\# 05$ & \multirow{7}{*}{ CL-V } & \multirow{7}{*}{$\mathrm{CL}(\mathrm{O}-\mathrm{I}) / 5$} & \multirow{7}{*}{ Chess } & 100 & 525 & 90 & 71 & \multirow{7}{*}{175} & \multirow{7}{*}{500} & \multirow{7}{*}{100} & \multirow{7}{*}{117} \\
\hline$\# 11$ & & & & 75 & 525 & 90 & 53 & & & & \\
\hline$\# 12$ & & & & 200 & 525 & 90 & 141 & & & & \\
\hline$\# 13$ & & & & 100 & 250 & 90 & 148 & & & & \\
\hline$\# 14$ & & & & 100 & 1050 & 90 & 35 & & & & \\
\hline$\# 15$ & & & & 100 & 525 & 60 & 106 & & & & \\
\hline$\# 16$ & & & & 100 & 525 & 120 & 53 & & & & \\
\hline
\end{tabular}

\subsubsection{Effect of Laser Power}

The influence of the laser power was studied with the samples manufactured with three different contour laser powers $\mathrm{P}_{\mathrm{CL}}=75 \mathrm{~W}$ (\#11), $100 \mathrm{~W}$ (\#05), $200 \mathrm{~W}$ (\#12) (Figure 8).

(a)

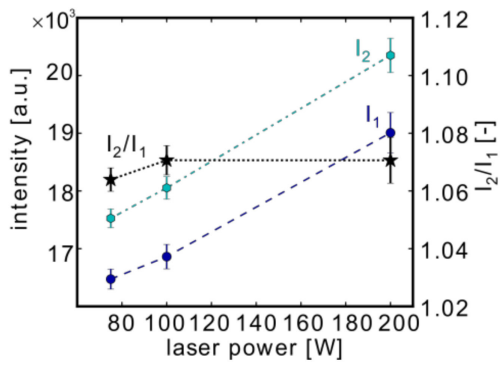

(b)

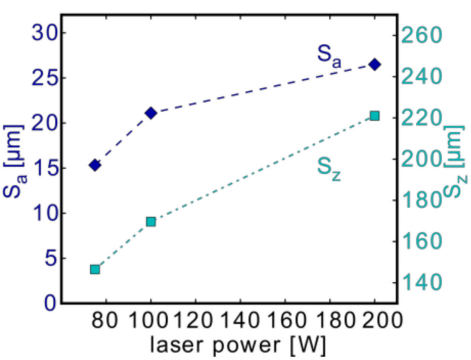

(c)

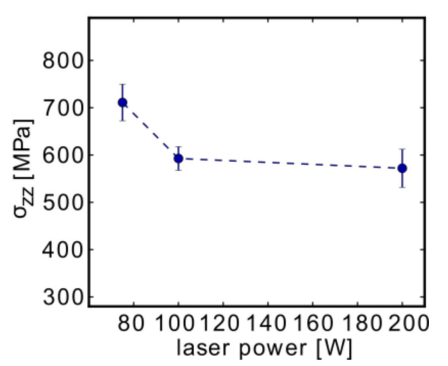

Figure 8. Influence of the power on the MPM data (a), on the surface roughness (b), and on the residual stresses (c). Depicted are the results from samples \#11 ( $\left.P_{C L}=75 \mathrm{~W}\right), \# 05\left(P_{C L}=100 \mathrm{~W}\right), \# 12\left(P_{C L}=200\right.$ $\mathrm{W})$. Note: The lines connecting the measurement points are only provided as a guide for the eye. 
The MPM intensities increased with $\mathrm{P}_{\mathrm{CL}}$ (Figure 8a), which is in agreement with simulations from Ref. [55] that show a rise in melt pool temperature with higher laser power. Due to the different sensitivity ranges of both photodiodes of the SLM Solution melt pool monitoring system and the shift in the wavelength of the thermal radiation maximum, the intensities rose in a different manner, and the intensity quotient did not change significantly. Only the scatter increased with higher laser power P.

The roughness showed a clear tendency in line with the results from the previous sections to increase at higher laser powers (Figure $8 b$ ). Conversely, $\sigma_{z z}$ yielded lower stresses when the energy density rose (Figure 8c). However, because only three different laser powers were investigated, the exact behavior between $100 \mathrm{~W}$ and $200 \mathrm{~W}$ was not well resolved.

\subsubsection{Effect of the Scanning Velocity}

The influence of the scanning velocity was investigated with samples \#13 (contour scanning velocity $\left.\mathrm{v}_{C L}=250 \mathrm{~mm} / \mathrm{s}\right), \# 05\left(\mathrm{v}_{C L}=525 \mathrm{~mm} / \mathrm{s}\right)$, and $\# 14\left(\mathrm{v}_{C L}=1050 \mathrm{~mm} / \mathrm{s}\right)$.

Both MPM intensities and the intensity quotient decreased with increasing contour scanning velocity (Figure 9a). This is qualitatively in accordance with higher melt pool temperatures obtained in simulations with decreasing scan velocities [56]. The same decreasing trend was observed for the roughness (Figure $9 \mathrm{~b} ; \mathrm{S}_{\mathrm{a}}$ : From 23.5 to $14.2 \mu \mathrm{m}$ ), whereas the stresses $\sigma_{\mathrm{zz}}$ in build direction (Figure $9 \mathrm{c}$ ) showed an increase from 507 to $625 \mathrm{MPa}$.

(a)

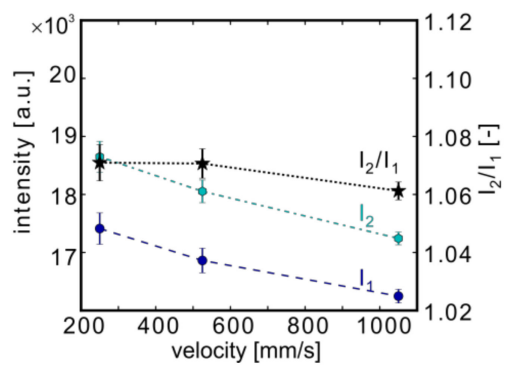

(b)

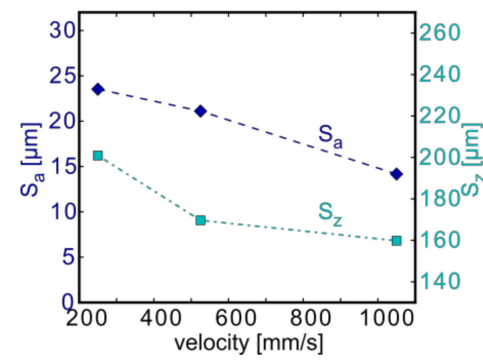

(c)

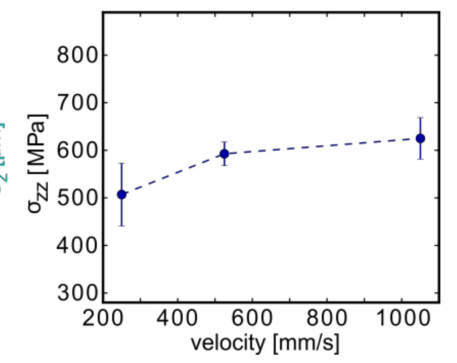

Figure 9. Influence of the scanning velocity on the MPM data (a), on the surface roughness (b), and on the residual stresses (c). Depicted are the results from samples \#13 (250 mm/s), \#05 (525 mm/s), and \#14 $(1050 \mathrm{~mm} / \mathrm{s})$. Note: The lines connecting the measurement points are only provided as a guide for the eye.

\subsubsection{Effect of the Hatch Distance}

For investigating the influence of the hatch distance on surface quality and residual stresses, samples with three different contour hatch distances were used: \#15 ( $\left.\mathrm{h}_{\mathrm{CL}}=60 \mu \mathrm{m}\right), \# 05\left(\mathrm{~h}_{\mathrm{CL}}=90 \mu \mathrm{m}\right)$, and $\# 16\left(\mathrm{~h}_{\mathrm{CL}}=120 \mu \mathrm{m}\right)$.

Only a slight influence of the hatch distance on the MPM data and the surface roughness could be observed in the investigated parameter range (Figure 10a,b). However, the typical variations caused by the LPBF process were of a similar order of magnitude. The influence on the residual stresses was slightly more pronounced, and higher stresses were obtained for larger hatch distances (Figure 10c). 
(a)

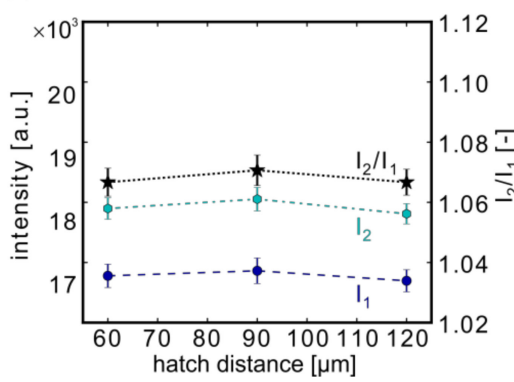

(b)

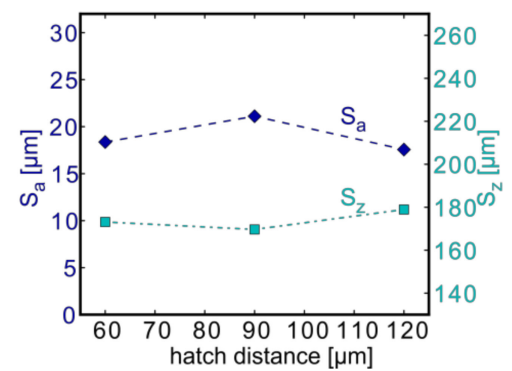

(c)

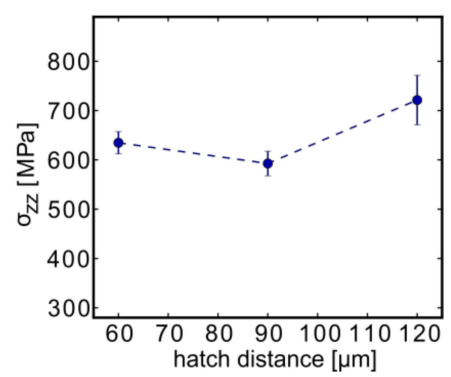

Figure 10. Influence of the hatch distance on the MPM data (a), on the surface roughness (b), and on

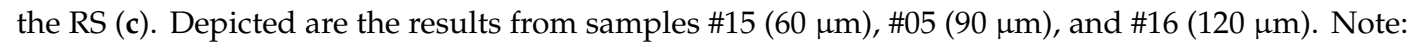
The lines connecting the measurement points are only provided as a guide for the eye.

\subsection{Effect of Changing $P, v$, and $h$ at $E_{v}=$ const.}

In the experiments described in Section 3.4, each laser parameter was varied separately. In the following set of samples, several laser parameters were changed simultaneously such that $E_{\mathrm{v}}$ was kept constant. Again, only a contour scan strategy was used and, thus, $\mathrm{P}_{\mathrm{CL}}, \mathrm{v}_{\mathrm{CL}}$, and $\mathrm{h}_{\mathrm{CL}}$ were varied (Table 5).

Table 5. Varying the main laser parameters, $\mathrm{E}_{\mathrm{V}}=$ const.

\begin{tabular}{|c|c|c|c|c|c|c|c|c|c|c|c|}
\hline No & $\begin{array}{l}\text { Scan } \\
\text { Order }\end{array}$ & $\begin{array}{l}\text { Scan strategy } \\
\text { Contour/\# of } \\
\text { Contour Lines }\end{array}$ & $\begin{array}{c}\text { Scan } \\
\text { Strategy } \\
\text { Volume }\end{array}$ & \multicolumn{4}{|c|}{ Contour Parameters } & \multicolumn{4}{|c|}{ Volume Parameters } \\
\hline$\# 05$ & \multirow{5}{*}{ CL-V } & \multirow{5}{*}{$\mathrm{CL}(\mathrm{O}-\mathrm{I}) / 5$} & \multirow{5}{*}{ Chess } & 100 & 525 & 90 & 71 & \multirow{5}{*}{175} & \multirow{5}{*}{500} & \multirow{5}{*}{100} & \multirow{5}{*}{117} \\
\hline \#17 & & & & 75 & 394 & 90 & 71 & & & & \\
\hline \#19 & & & & 300 & 1575 & 90 & 71 & & & & \\
\hline \#20 & & & & 66.7 & 525 & 60 & 71 & & & & \\
\hline \#21 & & & & 100 & 787.5 & 60 & 71 & & & & \\
\hline
\end{tabular}

The MPM intensities generally increased with the linked increase in laser power and scanning velocity (Figure 11a). If both laser parameters acted similarly, the MPM intensity should remain constant, such as $\mathrm{E}_{\mathrm{V}}$. However, the increase indicated that the influence of the laser power on the MPM intensity dominated the influence of the scanning velocity.

Comparable to the results of the independent power variation (Figure 8a), the trend of the intensity quotient $\mathrm{I}_{2} / \mathrm{I}_{1}$ differed from that of the single photodiode intensities. A maximum of $\mathrm{I}_{2} / \mathrm{I}_{1}$ was reached at $\mathrm{P}_{\mathrm{CL}}=100 \mathrm{~W}$, which decreased strongly towards $300 \mathrm{~W}$ (Figure 11a). The different hatch distances, in contrast, did not influence the MPM response.

The roughness $S_{a}$ (Figure 11b) followed the trend of the MPM intensity quotient. The surface roughness was rather low for a low laser power (and low $\mathrm{v}$ ) as well as for the highest chosen laser power (and v). At $\mathrm{P}_{\mathrm{CL}}=300 \mathrm{~W}$ and $1575 \mathrm{~mm} / \mathrm{s}$, the lowest surface roughness $\mathrm{S}_{\mathrm{a}} \approx 13 \mu \mathrm{m}$, in this study, was achieved.

The residual stresses opposed the roughness trend: they were higher for a low laser power (low v) as well as for a high laser power (high v), while in between, a minimum in the stresses was observed. In the independent single parameter variations (Section 3.4), $\sigma_{z z}$ increased with decreasing laser power and increased with higher scanning velocities. The observed trend with a simultaneous variation of $P$ and $\mathrm{v}$ at $\mathrm{E}_{\mathrm{V}}=$ const. suggests a change of the key factors when viewed in the context of the single parameter variations for $\mathrm{P}$ (Section 3.5; Figure 8c) and $\mathrm{v}$ (Figure 9c). For the combination of low $\mathrm{P}$ and low $\mathrm{v}$, the laser power appeared to be the important factor, leading to the slight $\sigma_{\mathrm{zz}}$ increase (a strong 
increase was observed for decreasing P, Figure 8c), whereas, at high $\mathrm{P}$ and high v, the scanning velocity might dominate the residual stress increase (increase at larger v, Figure 9c).
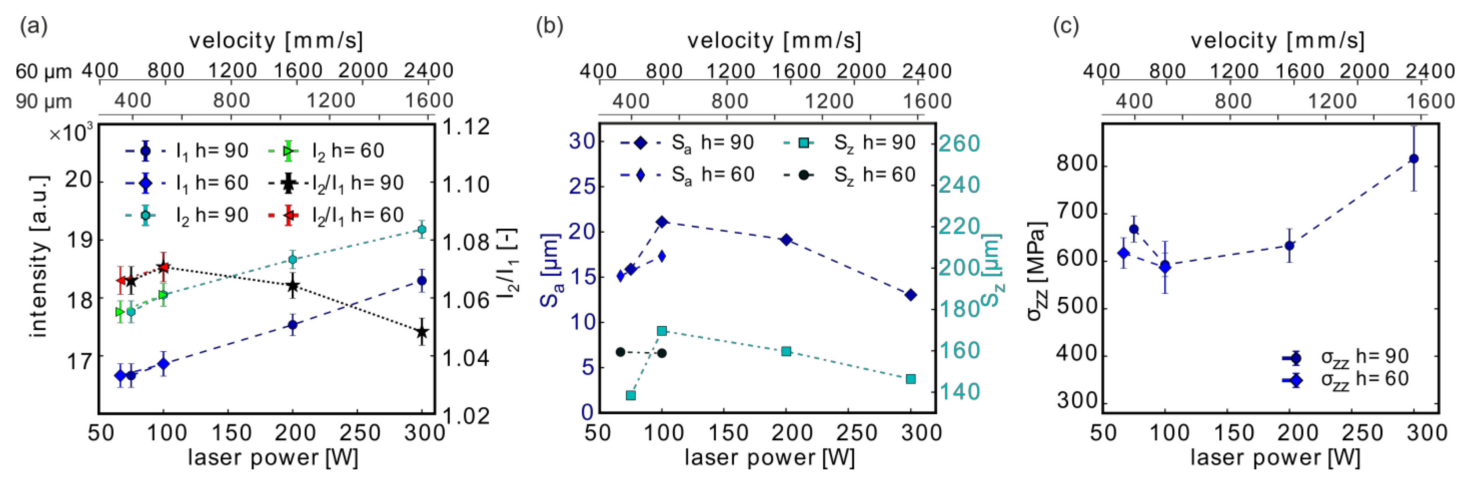

Figure 11. Effects of the laser power, scanning velocity, and hatch distance at constant volume energy density $\left(\mathrm{E}_{\mathrm{V}}=\right.$ const.) on the MPM data (a), on the surface roughness (b), and on the residual stresses (c). Depicted are the results of the samples listed in Table 5. The upper-velocity axis at the top of each Figure corresponds to the $h=60 \mu \mathrm{m}$ and the lower one to the $\mathrm{h}=90 \mu \mathrm{m}$ curves. Note: The lines connecting the measurement points are only provided as a guide for the eye.

\subsection{Effect of a Post-Processing Surface Treatment-Shot Peening}

One specimen (\#22), manufactured with the same LPBF processing parameters as used for sample $\# 09$, was shot-peened in a post-processing step. As a result, the surface roughness was reduced to $S_{a}=6.3 \mu \mathrm{m}$ and $S_{z}=67.5 \mu \mathrm{m}$ (Figure 12a). Furthermore, high compressive residual stresses in a range of $-800 \pm 40 \mathrm{MPa}$ were now obtained (from the $\{103\}$-Ti reflection at around $100 \mu \mathrm{m}$ ). The stresses were measured at the surface $(\mathrm{y}=0 \mu \mathrm{m})$. The compressive stresses were comparable to those of ca. -910 MPa reported for a similar treatment by Leuders et al. ( $R_{a}$ therein $4.2 \mu \mathrm{m}$ after shot peening) $[4,8]$.

(a)

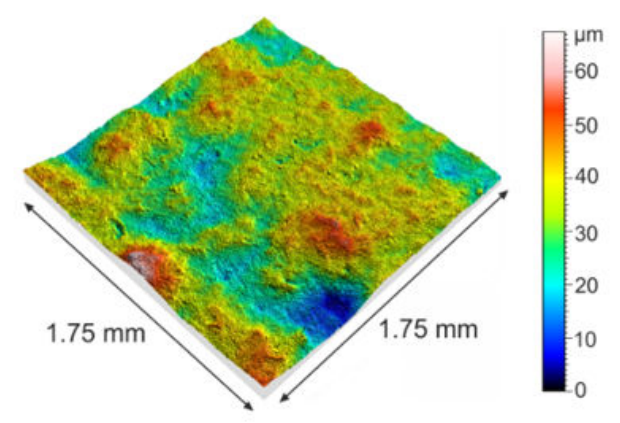

(b)

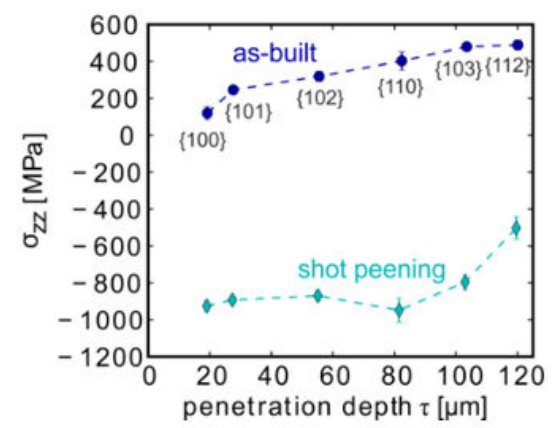

Figure 12. (a) LSM topography results of the shot-peened specimen (\#22); (b) stress depth profile for a shot-peened specimen relative to an as-built specimen (\#09 for $\mathrm{y}=0 \mu \mathrm{m}$ ). Each stress value belongs to a certain $\{\mathrm{hkl}\}$-peak, which is given in the brackets. The penetration depth $\tau$ was calculated according to Equation (3).

The high compressive stresses in coupon \#22 prevailed at the surface and were almost constant up to a penetration depth of $80 \mu \mathrm{m}$. In comparison, almost no stresses could be measured at the surface $(y=0 \mu \mathrm{m})$ of the as-built specimen, and only farther inside than $\sim 100 \mu \mathrm{m}$ tensile stresses were detected (see Methods Section for the choice of the sampling depth). 


\section{Discussion}

4.1. Identification of the Dominating Influence Factors from Laser Power, Scan Velocity, and Hatch Distance on MPM, Surface Quality, and Residual Stresses

The influence of the contour laser parameters (power, scanning velocity, and hatch distance) is presented separately in the Results Section 3.4. Rather than discussing the separate influences, the main observations shall be analyzed on a deeper level. The energy density $\mathrm{E}_{\mathrm{V}}$ is used in place of the specific laser process parameters (Figure 13) to identify trends that can assist LPBF parameter developments.

The MPM intensities $I_{1}$ and $I_{2}\left(I_{1}\right.$ is given in Figure $13 a, I_{2}$ is omitted for clarity) showed a positive correlation with $\mathrm{E}_{\mathrm{V}}$, which was due to raising the laser power $\mathrm{P}$ or slowing the scanning velocity v. The laser power had the largest influence on the intensity. This was in accordance with recent simulations that concluded that variations of the laser power had a larger influence on the melt pool temperature (and local temperature gradient) than variations of the scanning velocity $[55,56]$. The variation of the hatch distance $h$ only had a small influence on the MPM intensities of the outermost contour line because the inner contour and fill contour lines were printed after the outermost contour vector.

In contrast to the MPM single diode intensities, the quotient $\mathrm{I}_{2} / \mathrm{I}_{1}$ provided a slightly different behavior (Figure 13a). For low $\mathrm{E}_{\mathrm{V}}$, the quotient was smaller, but the strong increases in the single intensities canceled out, and $\mathrm{I}_{2} / \mathrm{I}_{1}$ stayed almost constant towards higher $\mathrm{E}_{\mathrm{V}}$. For the scanning velocity and the laser power variation, a plateau of the quotient around $I_{2} / I_{1} \approx 1.07$ was reached for $E_{V} \geq$ $70 \mathrm{~J} / \mathrm{mm}^{3}$.

(a)

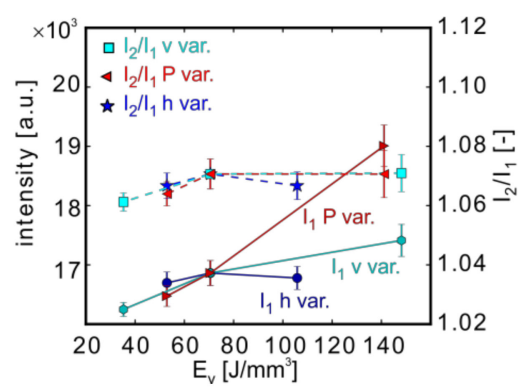

(b)

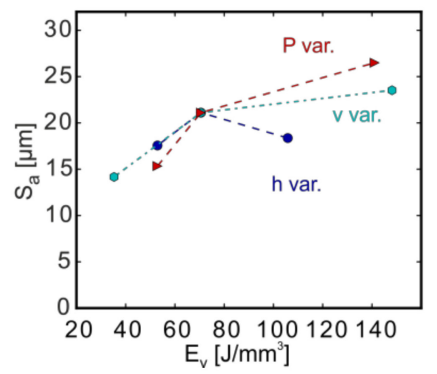

(c)

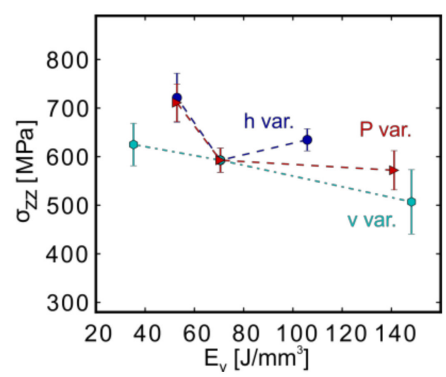

Figure 13. Comparison of the results for the variation of the hatch distance $h$, laser power $P$, and scanning velocity $v$ in relation to $E_{V}$ (details see Section 3.4) on the MPM data (a), on the surface roughness (b), and on the residual stresses (c).

Analogous to the single MPM intensities $\mathrm{I}_{1}$ and $\mathrm{I}_{2}$, the laser power had the highest influence on the roughness with the higher $S_{a}$ values being obtained for increasing $P$. The residual stresses showed an opposite trend: stresses in build direction $\sigma_{\mathrm{zZ}}$ tended to decrease with increasing $\mathrm{E}_{\mathrm{V}}$, which was in accordance with previous results [16]. However, relative to the comparably large variations of $S_{a}$ $(\sim 14.2$ to $26.5 \mu \mathrm{m})$ with $\mathrm{E}_{\mathrm{V}}$, the bandwidth of $\sigma_{\mathrm{zz}}$ was smaller $(\sim 500-720 \mathrm{MPa})$. Hence, $\mathrm{S}_{\mathrm{a}}$ appeared to be more sensitive to $E_{V}$ than $\sigma_{z z}$ within this set of samples.

\subsection{Correlation between Surface Roughness and Residual Stresses}

All measured residual stresses of the as-built specimens were tensile in nature, independent of the chosen scan pattern, scan order, or the chosen process parameters. The stresses in build direction $\sigma_{\mathrm{zz}}$ (between $338 \mathrm{MPa}$ and $816 \mathrm{MPa}$ ) were affected particularly strongly by the laser power, but also by the scan velocity (Figure 13a). The lowest $\sigma_{\mathrm{zz}}=338 \mathrm{MPa}$ was obtained for sample \#04, which was produced only with volume hatching at comparably high $\mathrm{P}=175 \mathrm{~W}$, resulting in a high $\mathrm{E}_{\mathrm{v}}$. In order to achieve overall low stresses $\sigma_{\mathrm{zz}}$, low velocities (Figure 9c) and the scan order "contour 
first (inside-outside), then volume hatching" (Figure 6) were favorable when contour and volume parameters were used together.

The arithmetic mean heights $S_{a}$ obtained in this study for the group of as-built samples varied between $13 \mu \mathrm{m}$ and $30 \mu \mathrm{m}$ and maximum heights $S_{z}$ between $138 \mu \mathrm{m}$ and $264 \mu \mathrm{m}$, suggesting that the use of an optimized LPBF contour strategy, as already generally recommended by machine producers, could improve surface qualities by a factor of up to $\sim 2$. High velocities, in combination with high laser powers, seem to be most promising in terms of a low roughness. The lowest values of $S_{a}$ reported in this study based on confocal microscopy were in a good agreement with those reported from characterization with contact-based 1D methods for LPBF Ti-6Al-4V: Greitemeier et al. [7] obtained roughness values of $\mathrm{R}_{\mathrm{a}} \approx 13.0 \mu \mathrm{m}$, and Leuders and coworkers [8] reported a value of ca. $18 \mu \mathrm{m}$ for the corresponding surface orientation $\left(90^{\circ}\right)$, with slightly different specimen geometries as used in this study.

Importantly, the optimization of the contour properties has to be viewed in the context of the correlation with the residual stresses because both $S_{a}$ and $S_{z}$ were linked to $\sigma_{z z}$ (Figure 14). High roughness values were correlated to low residual stresses and vice versa (Figure 14a).

(a)

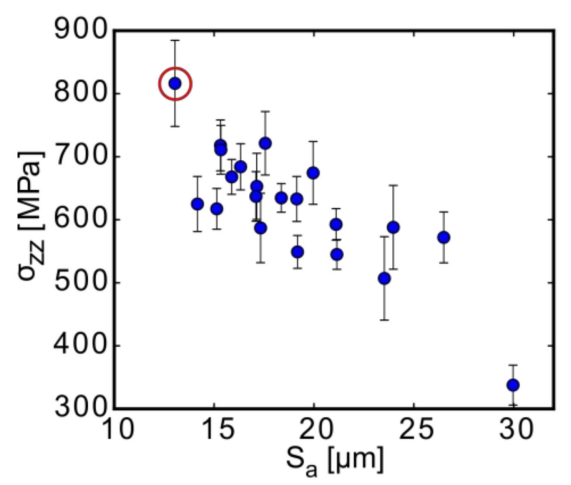

(b)

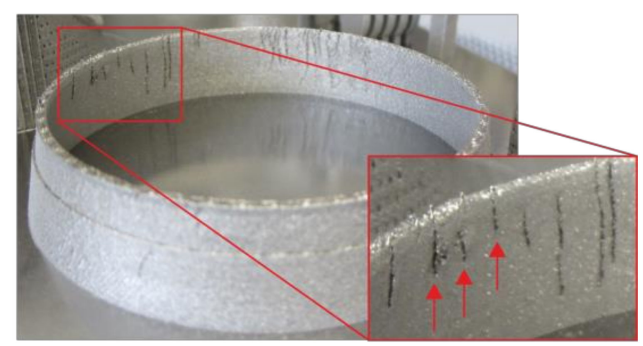

Figure 14. Correlation of the mean arithmetic height $S_{\mathrm{a}}$ with (a) the stress in build direction $\sigma_{\mathrm{zz}}$ and (b) image of a component (diameter $\sim 80 \mathrm{~mm}$, height $\sim 15 \mathrm{~mm}$ ) built with the same parameters that were used for sample \#19 and exhibited severe RS-induced cracking. Three examples of cracks are indicated by red arrows.

This reminds of Pandora's box: the roughness cannot be reduced without negatively affecting another important property, the residual stress. In fact, when using the contour strategy, giving the lowest, i.e., best roughness results (i.e., sample \#19), the residual stresses in build direction exceeded tolerable limits and led to substantial cracking in manufactured components. This can be seen in the example of a fuel injector ring with fine channels in Figure 14b (The stl.-file of the injector element was created with the CAD-software Inventor). While the surface roughness was low, the residual stresses were so large that cracks developed in the contour region near the internal channels during the build.

This example highlights that in AM process developments, each optimization step has to be carried out carefully, taking into account correlations, because typically different properties are affected differently at the same time. One explanation for the correlation of $\sigma_{z z}$ and $S_{a}$ in the case of high tensile stresses might be that the melt may have a high tendency to shrink (due to surface tension as evidenced, e.g., by balling effects) during the cooling process. If the melt tends to shrink, on the one hand, fewer powder particles will be attached to the welding tracks during solidification, lowering the surface roughness in turn. On the other hand, however, a high tendency to shrink could explain the simultaneously high residual stresses observed for the respective scan strategies, exhibiting improved surface qualities. 


\subsection{Correlation of MPM to Surface Roughness and Residual Stresses}

An analysis of the correlation between the MPM data and the arithmetic mean surface height $S_{a}$ showed that the monitoring might be used for obtaining a first prediction of the surface roughness that would be obtained with a specific LPBF parameter set (Figure 15a). The correlation was found to be better at the $I_{2} / I_{1}$ quotient than to any of the single intensities (see Supplementary Figure $S 4$ for correlations to $\mathrm{I}_{1}$ ). The correlation obtained for similar scan orders in Figure 15a related to higher $\mathrm{MPM} \mathrm{I}_{2} / \mathrm{I}_{1}$ values to higher surface roughness. For the specimens manufactured with high laser power belonging to the $P$ variation (Section 3.4), or $E_{v}=$ const $(h=90 \mu \mathrm{m})$ or $E_{v}=$ const. $(h=60 \mu \mathrm{m})$ series (Section 3.5) in Figure 15a, the trend was maintained, but it is striking that the samples belonging to the variation of the contour line number (CL var. in Figure 15a; Section 3.3) showed the best correlation. This might indicate that-once the correlation between roughness and MPM is known for one determined parameter set-the roughness can be predicted from the MPM data, which would be a considerable step towards quality monitoring.

(a)

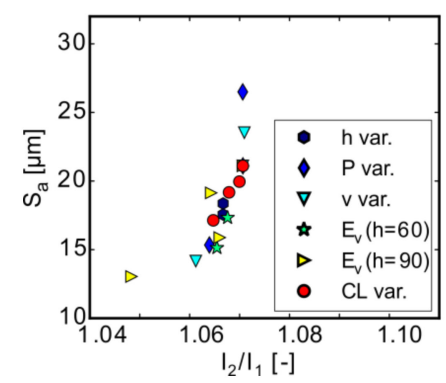

(b)

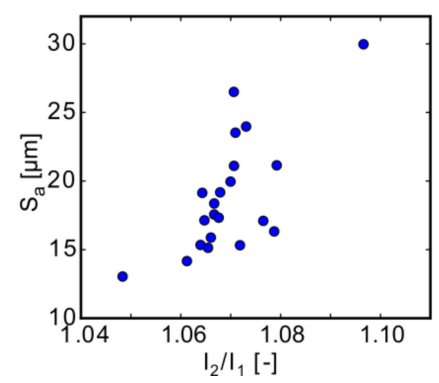

(c)

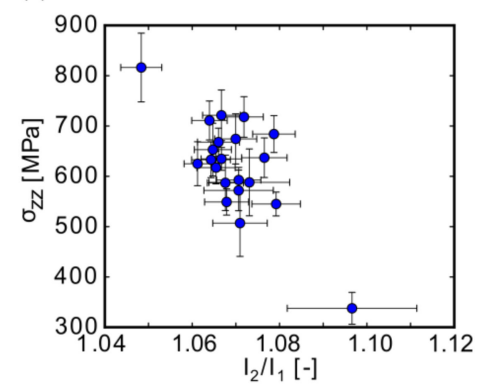

Figure 15. (a) Correlation of $S_{a}$ with $I_{2} / I_{1}$ for specimens, which were manufactured with contour lines and the standard scan order $\mathrm{CL}(\mathrm{O}-\mathrm{I})-\mathrm{V}$. The following samples are depicted: hatch distance variation (h var.), Section 3.4. (c); laser power variation (P. var), Section 3.4. (a); velocity variation (v var.), Section 3.4. (b); samples from the studies with hatch distances of $60 \mu \mathrm{m}$ and $=90 \mu \mathrm{m}$ at $\mathrm{E}_{\mathrm{V}}=$ const. $(\mathrm{h}=60 \mu \mathrm{m}$ and $\mathrm{h}=90 \mu \mathrm{m}$ ), Section 3.5; samples from the contour line (CL var), Section 3.3. (b) Correlation of $\mathrm{S}_{\mathrm{a}}$ with $\mathrm{I}_{2} / \mathrm{I}_{1}$ for all specimens. (c) Correlation of the residual stress in build direction $\sigma_{\mathrm{zz}}$ with $\mathrm{I}_{2} / \mathrm{I}_{1}$.

Importantly, this correlation works best in cases following the same scan strategy, i.e., particularly the scan order (cp. Figure 15a,b): While (a) contains only data points following a similar scan order (standard: contour lines (outside to inside), followed by volume) and provides a good correlation between $\mathrm{I}_{2} / \mathrm{I}_{1}$ and $\mathrm{S}_{\mathrm{a}}$, (b) also contains additional data points from the samples manufactured with different scan orders. A better correlation for similar scan orders can be understood from the behavior observed in Section 3.2: the MPM intensities were influenced sizably by the scan order of the contour lines (I-O versus O-I; Figure 6a), but the surface roughness was affected only slightly (Figure 6b). Hence, the estimate of the roughness value from the MPM data will be less reliable if the scan order in the contour region is changed.

Similarly, the MPM signals, again particularly $\mathrm{I}_{2} / \mathrm{I}_{1}$, and the residual stresses of the respective samples seemed to follow a rough correlation that might provide a means to estimate residual stresses from in situ process monitoring (Figure 15). This is not surprising in the light of the correlation between $S_{a}$ and $\sigma_{z z}$ discussed above (Figure 14): samples having shown high MPM intensities during LPBF consequently exhibited lower stresses in build direction $\sigma_{\mathrm{zz}}$.

\section{Conclusions}

In this study, 21 different scan strategies in LPBF of Ti-6Al-4V were studied systematically at the coupon level, and their effects on surface qualities and subsurface residual stresses were analyzed. Correlations between the laser scan strategies, the respective laser parameters, and the 
surface roughness, as well as the residual stresses (in the as-built condition), were identified. The LPBF build was monitored in situ with the integrated photodiode-based melt pool monitoring system. The following main results were obtained:

- $\quad \mathrm{S}_{\mathrm{a}}$ and near-surface residual stresses $\sigma_{\mathrm{zz}}$ were intrinsically linked in the LPBF specimens.

- The ranges obtained for $S_{a}$ and $\sigma_{z z}$ implied a large potential for an optimization of the LPBF parameters, although due to the link between both and their inverse dependence on the laser power and scan velocity, this optimization might only result in a Pareto optimum. For the investigated sample geometry, the stresses in the build direction $\sigma_{\mathrm{zz}}$ increased up to a level at which macroscopic cracking in manufactured components occurred, when contour strategies focusing primarily on lowering the surface roughness were employed.

- Therefore, any parameter optimization has to be carried out carefully. An optimal contour scan strategy with vectors processed first from the outside and then on the inside (at $100 \mathrm{~W}, 1050 \mathrm{~mm} / \mathrm{s}$, and $90 \mu \mathrm{m}$ contour hatch distance) prior to volume hatching can be recommended based on the analyzed Ti-6Al-4V samples. This strategy represents a trade-off between RS and roughness $\left(\sigma_{\mathrm{zz}}=625 \mathrm{MPa}, \mathrm{S}_{\mathrm{a}}=14.2 \mu \mathrm{m}\right)$.

- The MPM monitoring may be suitable to estimate the surface roughness from the intensity quotient $\mathrm{I}_{2} / \mathrm{I}_{1}$ of the two photodiodes: A correlation between $\mathrm{I}_{2} / \mathrm{I}_{1}$ and $\mathrm{S}_{\mathrm{a}}$ was discovered particularly for groups of samples manufactured with similar contour strategies, e.g., for samples printed with the scan order "contour vectors (from outside to the inside), followed by volume hatching". Due to the link between $S_{a}$ and $\sigma_{z z}$, the MPM data $I_{2} / I_{1}$ can also be used to estimate the resulting residual stresses in the LPBF material. The predictive estimates of $S_{a}$ and $\sigma_{z z}$ from the melt pool monitoring during the LPBF process can be useful for the development of build strategies and parameter adaption in complex components.

Further studies are required in order to elucidate and transfer these results to different coupon geometries exhibiting, e.g., up- and down-skin surfaces. The current results may provide helpful insights for the analysis of the underlying mechanisms for residual stress build-up and redistribution from thermal simulations of the LPBF process.

Supplementary Materials: The following materials are available online at http://www.mdpi.com/1996-1944/13/15/ 3348/s1, Table S1: Measured values: MPM data, surface roughness data, and residual stress components, Figure S1: Diffractograms for different $\psi$-angles, measuring depths, integrated peak intensities and RS in build direction, Figure S2: LSM topology data of selected samples, Figure S3: The analysis of the potential correlations between stresses perpendicular to the build direction $\sigma_{\mathrm{xx}}$ and in-build direction $\sigma_{\mathrm{zz}}$, Figure S4: Comparison of $\mathrm{S}_{\mathrm{a}}$ with $\mathrm{I}_{1}$ as well as $\sigma_{z z}$ with $I_{1}$ for all specimens.

Author Contributions: Conceptualization, K.A., J.H., G.R. and G.B.; methodology, K.A., T.M. and J.H.; formal analysis, K.A. and T.M.; experimental investigation, K.A., T.M., J.G., P.-P.B., P.B.-V. and S.E.; writing-original draft preparation: K.A. and J.H.; writing - review and editing: all authors. All authors have read and agreed to the published version of the manuscript.

Funding: This research received no external funding.

Acknowledgments: T. Merzouk and A. Turak are acknowledged for operating the SLM machine and manufacturing of the samples at DLR. M. Ortelt, DLR Institute of Design a Structure Technology, Stuttgart, is thanked for providing the CAD file of the injector. Authors thank M. Klaus and Ch. Genzel (Helmholz Zentrum Berlin) for the support during beamtime.

Conflicts of Interest: The authors declare no conflict of interest. 


\section{Appendix A}

Table A1. Summary of all specimens manufactured with LPBF using different scan strategies for the current study. Sample \#09 corresponds to the SLM Solution standard scan strategy.

\begin{tabular}{|c|c|c|c|c|c|c|c|c|c|c|c|c|}
\hline \multirow[b]{2}{*}{ No } & \multirow[b]{2}{*}{$\begin{array}{l}\text { Scan } \\
\text { Order }\end{array}$} & \multirow[b]{2}{*}{$\begin{array}{l}\text { Scan Strategy } \\
\text { Contour/\# of } \\
\text { Contour Lines }\end{array}$} & \multirow[b]{2}{*}{$\begin{array}{l}\text { Scan } \\
\text { Strategy } \\
\text { Volume }\end{array}$} & \multicolumn{4}{|c|}{ Contour Parameters } & \multicolumn{4}{|c|}{ Volume Parameters } & \multirow[b]{2}{*}{ Scan Pattern } \\
\hline & & & & $\begin{array}{c}\text { Power } \\
P_{C L}(W)\end{array}$ & $\begin{array}{c}\text { Scan vel. } \\
\text { vCL } \\
(\mathrm{mm} / \mathrm{s})\end{array}$ & $\begin{array}{c}\text { Hatch } \\
\mathrm{h}_{\mathrm{CL}}(\mu \mathrm{m})\end{array}$ & $\mathrm{E}_{\mathrm{v}, \mathrm{cl}}\left(\mathrm{J} / \mathrm{mm}^{3}\right)$ & $\begin{array}{l}\text { Power } \\
P(W)\end{array}$ & $\begin{array}{l}\text { Scan vel. } \\
\mathrm{v}(\mathrm{mm} / \mathrm{s})\end{array}$ & $\begin{array}{l}\text { Hatch } \\
\mathrm{h}(\mu \mathrm{m})\end{array}$ & $\begin{array}{c}E_{v} \\
\left(J / \mathrm{mm}^{3}\right)\end{array}$ & \\
\hline \#01 & CL & $\begin{array}{c}\mathrm{CL}(\mathrm{O}-\mathrm{I}) \\
/ \infty\end{array}$ & - & 100 & 525 & 90 & 71 & - & - & - & - & \\
\hline$\# 02$ & - & $\mathrm{CL}(\mathrm{I}-\mathrm{O}) / \infty$ & - & 100 & 525 & 90 & 71 & - & - & - & - & \\
\hline$\# 03$ & V & $-/ 0$ & Chess & - & - & - & - & 100 & 525 & 90 & 71 & \\
\hline \#04 & V & $-/ 0$ & Chess & - & - & - & - & 175 & 500 & 100 & 117 & \\
\hline \#05 & CL-V & $\mathrm{CL}(\mathrm{O}-\mathrm{I}) / 5$ & Chess & 100 & 525 & 90 & 71 & 175 & 500 & 100 & 117 & \\
\hline \#06 & $\mathrm{CL}-\mathrm{V}$ & $\mathrm{CL}(\mathrm{I}-\mathrm{O}) / 5$ & Chess & 100 & 525 & 90 & 71 & 175 & 500 & 100 & 117 & \\
\hline
\end{tabular}


Table A1. Cont.

\begin{tabular}{|c|c|c|c|c|c|c|c|c|c|c|c|c|}
\hline \multirow[b]{2}{*}{ No } & \multirow[b]{2}{*}{$\begin{array}{l}\text { Scan } \\
\text { Order }\end{array}$} & \multirow[b]{2}{*}{$\begin{array}{l}\text { Scan Strategy } \\
\text { Contour/\# of } \\
\text { Contour Lines }\end{array}$} & \multirow[b]{2}{*}{$\begin{array}{l}\text { Scan } \\
\text { Strategy } \\
\text { Volume }\end{array}$} & \multicolumn{4}{|c|}{ Contour Parameters } & \multicolumn{4}{|c|}{ Volume Parameters } & \multirow[b]{2}{*}{ Scan Pattern } \\
\hline & & & & $\begin{array}{c}\text { Power } \\
\text { P }_{C L}(W)\end{array}$ & $\begin{array}{c}\text { Scan vel. } \\
\text { vCL } \\
(\mathrm{mm} / \mathrm{s})\end{array}$ & $\begin{array}{c}\text { Hatch } \\
\mathrm{h}_{\mathrm{CL}}(\mu \mathrm{m})\end{array}$ & $E_{v, c l}\left(J / m^{3}\right)$ & $\begin{array}{c}\text { Power } \\
\text { P (W) }\end{array}$ & $\begin{array}{l}\text { Scan vel. } \\
\text { v (mm/s) }\end{array}$ & $\begin{array}{l}\text { Hatch } \\
\mathrm{h}(\mu \mathrm{m})\end{array}$ & $\begin{array}{c}E_{V} \\
\left(J / \mathrm{mm}^{3}\right)\end{array}$ & \\
\hline$\# 07$ & $\mathrm{~V}-\mathrm{CL}$ & $\mathrm{CL}(\mathrm{I}-\mathrm{O}) / 5$ & Chess & 100 & 525 & 90 & 71 & 175 & 500 & 100 & 117 & \\
\hline$\# 08$ & $\mathrm{~V}-\mathrm{CL}$ & $\mathrm{CL}(\mathrm{O}-\mathrm{I}) / 5$ & Chess & 100 & 525 & 90 & 71 & 175 & 500 & 100 & 117 & \\
\hline$\# 09$ & CL-V & $\mathrm{CL}(\mathrm{O}-\mathrm{I}) / 2$ & Chess & 100 & 525 & 90 & 71 & 175 & 500 & 100 & 117 & \\
\hline$\# 10$ & CL-V & $\mathrm{CL}(\mathrm{O}-\mathrm{I}) / 10$ & Chess & 100 & 525 & 90 & 71 & 175 & 500 & 100 & 117 & \\
\hline$\# 11$ & CL-V & $\mathrm{CL}(\mathrm{O}-\mathrm{I}) / 5$ & Chess & 75 & 525 & 90 & 53 & 175 & 500 & 100 & 117 & \\
\hline$\# 12$ & CL-V & $\mathrm{CL}(\mathrm{O}-\mathrm{I}) / 5$ & Chess & 200 & 525 & 90 & 141 & 175 & 500 & 100 & 117 & \\
\hline
\end{tabular}


Table A1. Cont.

\begin{tabular}{|c|c|c|c|c|c|c|c|c|c|c|c|c|}
\hline \multirow[b]{2}{*}{ No } & \multirow[b]{2}{*}{$\begin{array}{l}\text { Scan } \\
\text { Order }\end{array}$} & \multirow[b]{2}{*}{$\begin{array}{l}\text { Scan Strategy } \\
\text { Contour/\# of } \\
\text { Contour Lines }\end{array}$} & \multirow[b]{2}{*}{$\begin{array}{c}\text { Scan } \\
\text { Strategy } \\
\text { Volume }\end{array}$} & \multicolumn{4}{|c|}{ Contour Parameters } & \multicolumn{4}{|c|}{ Volume Parameters } & \multirow[b]{2}{*}{ Scan Pattern } \\
\hline & & & & $\begin{array}{c}\text { Power } \\
\text { P }_{C L}(W)\end{array}$ & $\begin{array}{c}\text { Scan vel. } \\
\text { vCL } \\
(\mathrm{mm} / \mathrm{s})\end{array}$ & $\begin{array}{c}\text { Hatch } \\
\mathrm{h}_{\mathrm{CL}}(\mu \mathrm{m})\end{array}$ & $E_{v, c l}\left(J / m^{3}\right)$ & $\begin{array}{l}\text { Power } \\
P(W)\end{array}$ & $\begin{array}{l}\text { Scan vel. } \\
\text { v ( } \mathrm{mm} / \mathrm{s})\end{array}$ & $\begin{array}{l}\text { Hatch } \\
\mathrm{h}(\mu \mathrm{m})\end{array}$ & $\begin{array}{c}E_{v} \\
\left(J / \mathrm{mm}^{3}\right)\end{array}$ & \\
\hline$\# 13$ & $\mathrm{CL}-\mathrm{V}$ & $\mathrm{CL}(\mathrm{O}-\mathrm{I}) / 5$ & Chess & 100 & 250 & 90 & 148 & 175 & 500 & 100 & 117 & \\
\hline$\# 14$ & $\mathrm{CL}-\mathrm{V}$ & $\mathrm{CL}(\mathrm{O}-\mathrm{I}) / 5$ & Chess & 100 & 1050 & 90 & 35 & 175 & 500 & 100 & 117 & \\
\hline \#15 & CL-V & $\mathrm{CL}(\mathrm{O}-\mathrm{I}) / 5$ & Chess & 100 & 525 & 60 & 106 & 175 & 500 & 100 & 117 & \\
\hline \#16 & CL-V & $\mathrm{CL}(\mathrm{O}-\mathrm{I}) / 5$ & Chess & 100 & 525 & 120 & 53 & 175 & 500 & 100 & 117 & \\
\hline$\# 17$ & CL-V & $\mathrm{CL}(\mathrm{O}-\mathrm{I}) / 5$ & Chess & 75 & 394 & 90 & 71 & 175 & 500 & 100 & 117 & \\
\hline$\# 18$ & $\mathrm{CL}-\mathrm{V}$ & $\mathrm{CL}(\mathrm{O}-\mathrm{I}) / 5$ & Chess & 200 & 1050 & 90 & 71 & 175 & 500 & 100 & 117 & \\
\hline
\end{tabular}


Table A1. Cont.

\begin{tabular}{|c|c|c|c|c|c|c|c|c|c|c|c|c|}
\hline \multirow[b]{2}{*}{ No } & \multirow[b]{2}{*}{$\begin{array}{l}\text { Scan } \\
\text { Order }\end{array}$} & \multirow[b]{2}{*}{$\begin{array}{l}\text { Scan Strategy } \\
\text { Contour/\# of } \\
\text { Contour Lines }\end{array}$} & \multirow[b]{2}{*}{$\begin{array}{l}\text { Scan } \\
\text { Strategy } \\
\text { Volume }\end{array}$} & \multicolumn{4}{|c|}{ Contour Parameters } & \multicolumn{4}{|c|}{ Volume Parameters } & \multirow[b]{2}{*}{ Scan Pattern } \\
\hline & & & & $\begin{array}{c}\text { Power } \\
P_{C L}(W)\end{array}$ & $\begin{array}{c}\text { Scan vel. } \\
\text { vCL } \\
(\mathrm{mm} / \mathrm{s})\end{array}$ & $\begin{array}{c}\text { Hatch } \\
\mathrm{h}_{\mathrm{CL}}(\mu \mathrm{m})\end{array}$ & $\mathrm{E}_{\mathrm{v}, \mathrm{cl}}\left(\mathrm{J} / \mathrm{mm}^{3}\right)$ & $\begin{array}{l}\text { Power } \\
P(W)\end{array}$ & $\begin{array}{l}\text { Scan vel. } \\
\mathrm{v}(\mathrm{mm} / \mathrm{s})\end{array}$ & $\begin{array}{l}\text { Hatch } \\
\mathrm{h}(\mu \mathrm{m})\end{array}$ & $\begin{array}{c}E_{V} \\
\left(J / \mathrm{mm}^{3}\right)\end{array}$ & \\
\hline \#19 & $\mathrm{CL}-\mathrm{V}$ & $\mathrm{CL}(\mathrm{O}-\mathrm{I}) / 5$ & Chess & 300 & 1575 & 90 & 71 & 175 & 500 & 100 & 117 & \\
\hline$\# 20$ & CL-V & $\mathrm{CL}(\mathrm{O}-\mathrm{I}) / 5$ & Chess & 66.7 & 525 & 60 & 71 & 175 & 500 & 100 & 117 & \\
\hline \#21 & CL-V & $\mathrm{CL}(\mathrm{O}-\mathrm{I}) / 5$ & Chess & 100 & 787.5 & 60 & 71 & 175 & 500 & 100 & 117 & \\
\hline
\end{tabular}




\section{References}

1. Dutta, B.; Froes, F.H. Chapter 1-The Additive Manufacturing of Titanium Alloys. In Additive Manufacturing of Titanium Alloys; Dutta, B., Froes, F.H., Eds.; Butterworth-Heinemann: Kidlington, UK, 2016; pp. 1-10. [CrossRef]

2. ISO/ASTM 52900. Additive Manufacturing-General Principles-Terminology; Beuth Verlag: Berlin, Germany, 2016.

3. Gibson, I.; Rosen, D.W.; Stucker, B. Design for Additive Manufacturing. In Additive Manufacturing Technologies: Rapid Prototyping to Direct Digital Manufacturing; Springer: Boston, MA, USA, 2010; pp. 299-332. [CrossRef]

4. Gunther, J.; Leuders, S.; Koppa, P.; Troster, T.; Henkel, S.; Biermann, H.; Niendorf, T. On the effect of internal channels and surface roughness on the high-cycle fatigue performance of Ti-6Al-4V processed by SLM. Mat. Des. 2018, 143, 1-11. [CrossRef]

5. Chen, Z.; Wu, X.; Tomus, D.; Davies, C.H.J. Surface roughness of Selective Laser Melted Ti-6Al-4V alloy components. Addit. Manuf. 2018, 21, 91-103. [CrossRef]

6. Gebhardt, A.; Hötter, J.-S.; Ziebura, D. Impact of SLM build parameters on the surface quality. RTejournal-Forum für Rapid Technologie. 2014. Available online: https://www.rtejournal.de/ausgabe11/3852 (accessed on 28 July 2020).

7. Greitemeier, D.; Dalle Donne, C.; Syassen, F.; Eufinger, J.; Melz, T. Effect of surface roughness on fatigue performance of additive manufactured Ti-6Al-4V. Mat. Sci. Tech. 2016, 32, 629-634. [CrossRef]

8. Leuders, S.; Meiners, S.; Wu, L.; Taube, A.; Troster, T.; Niendorf, T. Structural components manufactured by Selective Laser Melting and Investment Casting-Impact of the process route on the damage mechanism under cyclic loading. J. Mat. Proc. Tech. 2017, 248, 130-142. [CrossRef]

9. DebRoy, T.; Wei, H.L.; Zuback, J.S.; Mukherjee, T.; Elmer, J.W.; Milewski, J.O.; Beese, A.M.; Wilson-Heid, A.; De, A.; Zhang, W. Additive manufacturing of metallic components-Process, structure and properties. Prog. Mat. Sci. 2018, 92, 112-224. [CrossRef]

10. Kruth, J.P.; Deckers, J.; Yasa, E.; Wauthle, R. Assessing and comparing influencing factors of residual stresses in selective laser melting using a novel analysis method. Proc. Inst. Mech. Eng. Part B J. Eng. Manuf. 2012, 226, 980-991. [CrossRef]

11. Ali, H.; Ghadbeigi, H.; Mumtaz, K. Effect of scanning strategies on residual stress and mechanical properties of Selective Laser Melted Ti6Al4V. Mat. Sci. Eng. A 2018, 712, 175-187. [CrossRef]

12. Mishurova, T.; Artzt, K.; Haubrich, J.; Requena, G.; Bruno, G. Exploring the Correlation between Subsurface Residual Stresses and Manufacturing Parameters in Laser Powder Bed Fused Ti-6Al-4V. Metals 2019, 9. [CrossRef]

13. Mishurova, T.; Artzt, K.; Haubrich, J.; Requena, G.; Bruno, G. New aspects about the search for the most relevant parameters optimizing SLM materials. Addit. Manuf. 2019, 25, 325-334. [CrossRef]

14. Robinson, J.H.; Ashton, I.R.T.; Jones, E.; Fox, P.; Sutcliffe, C. The effect of hatch angle rotation on parts manufactured using selective laser melting. Rapid Protot. J. 2019, 25, 289-298. [CrossRef]

15. Song, J.; Wu, W.; Zhang, L.; He, B.; Lu, L.; Ni, X.; Long, Q.; Zhu, G. Role of scanning strategy on residual stress distribution in Ti-6Al-4V alloy prepared by selective laser melting. Optik 2018, 170, 342-352. [CrossRef]

16. Mishurova, T.; Cabeza, S.; Artzt, K.; Haubrich, J.; Klaus, M.; Genzel, C.; Requena, G.; Bruno, G. An Assessment of Subsurface Residual Stress Analysis in SLM Ti-6Al-4V. Materials 2017, 10. [CrossRef] [PubMed]

17. Mercelis, P.; Kruth, J.P. Residual stresses in selective laser sintering and selective laser melting. Rapid Prototyp. J. 2006, 12, 254-265. [CrossRef]

18. Yadroitsev, I.; Yadroitsava, I. Evaluation of residual stress in stainless steel 316L and Ti6Al4V samples produced by selective laser melting. Virtual Phys. Prototyp. 2015, 10, 67-76. [CrossRef]

19. Patterson, A.E.; Messimer, S.L.; Farrington, P.A. Overhanging Features and the SLM/DMLS Residual Stresses Problem: Review and Future Research Need. Technologies 2017, 5, 15. [CrossRef]

20. Mishurova, T.; Cabeza, S.; Thiede, T.; Nadammal, N.; Kromm, A.; Klaus, M.; Genzel, C.; Haberland, C.; Bruno, G. The Influence of the Support Structure on Residual Stress and Distortion in SLM Inconel 718 Parts. Met. Mat. Trans. A Phys. Metall. 2018, 49, 3038-3046. [CrossRef]

21. Ahmad, B.; van der Veen, S.O.; Fitzpatrick, M.E.; Guo, H. Residual stress evaluation in selective-laser-melting additively manufactured titanium (Ti-6Al-4V) and inconel 718 using the contour method and numerical simulation. Addit. Manuf. 2018, 22, 571-582. [CrossRef] 
22. Eskandari Sabzi, H. Powder bed fusion additive layer manufacturing of titanium alloys. Mat. Sci. Tech. 2019, 35, 875-890. [CrossRef]

23. Donachie, M.J. Titanium: A Technical Guide; ASM International: ASM World Headquarters—Materials Park: Novelty, OH, USA, 2000.

24. Vilaro, T.; Colin, C.; Bartout, J.D. As-Fabricated and Heat-Treated Microstructures of the Ti-6Al-4V Alloy Processed by Selective Laser Melting. Met. Mat. Trans. A Phys. Metall. 2011, 42A, 3190-3199. [CrossRef]

25. Xu, W.; Brandt, M.; Sun, S.; Elambasseril, J.; Liu, Q.; Latham, K.; Xia, K.; Qian, M. Additive manufacturing of strong and ductile Ti-6Al-4V by selective laser melting via in situ martensite decomposition. Acta Mat. 2015, 85, 74-84. [CrossRef]

26. Haubrich, J.; Gussone, J.; Barriobero-Vila, P.; Kurnsteiner, P.; Jagle, E.A.; Raabe, D.; Schell, N.; Requena, G. The role of lattice defects, element partitioning and intrinsic heat effects on the microstructure in selective laser melted Ti-6Al-4V. Acta Mat. 2019, 167, 136-148. [CrossRef]

27. Thombansen, U.; Gatej, A.; Pereira, M. Process observation in fiber laser-based selective laser melting. Optic. Eng. 2014, 54, 011008. [CrossRef]

28. SLM Solutions Group Home Page. Available online: https://www.slm-solutions.com/en/products/software/ additivequality/ (accessed on 3 May 2019).

29. Sigma Labs Home Page. Available online: https://sigmalabsinc.com/ (accessed on 5 March 2019).

30. 3D Systems Home Page. Available online: https://www.concept-laser.de/contact_usa/in-situ-qualityassurance-with-qmmeltpool-3d-from-concept-laser/ (accessed on 5 March 2019).

31. DMP Monitoring Home Page. Available online: https://www.3dsystems.com/dmp-monitoring-solution (accessed on 5 March 2019).

32. Berumen, S.; Bechmann, F.; Lindner, S.; Kruth, J.-P.; Craeghs, T. Quality control of laser- and powder bed-based Additive Manufacturing (AM) technologies. Phys. Proc. 2010, 5, 617-622. [CrossRef]

33. Chivel, Y.; Smurov, I. On-line temperature monitoring in selective laser sintering/melting. Phys. Proc. 2010, 5, 515-521. [CrossRef]

34. Clijsters, S.; Craeghs, T.; Buls, S.; Kempen, K.; Kruth, J.-P. In situ quality control of the selective laser melting process using a high-speed, real-time melt pool monitoring system. Int. J. Adv. Man. Tech. 2014, 75, 1089-1101. [CrossRef]

35. Craeghs, T.; Bechmann, F.; Berumen, S.; Kruth, J.-P. Feedback control of Layerwise Laser Melting using optical sensors. Phys. Proc. 2010, 5, 505-514. [CrossRef]

36. Pavlov, M.; Doubenskaia, M.; Smurov, I. Pyrometric analysis of thermal processes in SLM technology. Phys. Proc. 2010, 5, 523-531. [CrossRef]

37. Lott, P.; Schleifenbaum, H.; Meiners, W.; Wissenbach, K.; Hinke, C.; Bültmann, J. Design of an Optical system for the In Situ Process Monitoring of Selective Laser Melting (SLM). Phys. Proc. 2011, 12, 683-690. [CrossRef]

38. Craeghs, T.; Clijsters, S.; Kruth, J.P.; Bechmann, F.; Ebert, M.C. Detection of Process Failures in Layerwise Laser Melting with Optical Process Monitoring. Phys. Proc. 2012, 39, 753-759. [CrossRef]

39. Bisht, M.; Ray, N.; Verbist, F.; Coeck, S. Correlation of selective laser melting-melt pool events with the tensile properties of Ti-6Al-4V ELI processed by laser powder bed fusion. Addit. Manuf. 2018, 22, 302-306. [CrossRef]

40. Coeck, S.; Bisht, M.; Plas, J.; Verbist, F. Prediction of lack of fusion porosity in selective laser melting based on melt pool monitoring data. Addit. Manuf. 2019, 25, 347-356. [CrossRef]

41. Lu, Q.Y.; Wong, C.H. Additive manufacturing process monitoring and control by non-destructive testing techniques: Challenges and in-process monitoring. Virt. Phys. Prototyp. 2018, 13, 39-48. [CrossRef]

42. Everton, S.K.; Hirsch, M.; Stravroulakis, P.; Leach, R.K.; Clare, A.T. Review of in-situ process monitoring and in-situ metrology for metal additive manufacturing. Mat. Des. 2016, 95, 431-445. [CrossRef]

43. Mani, M.; Lane, B.M.; Donmez, M.A.; Feng, S.C.; Moylan, S.P. A review on measurement science needs for real-time control of additive manufacturing metal powder bed fusion processes. Int. J. Prod. Res. 2017, 55, 1400-1418. [CrossRef]

44. Spears, T.G.; Gold, S.A. In-process sensing in selective laser melting (SLM) additive manufacturing. Integr. Mat. Manuf. Innov. 2016, 5, 2. [CrossRef]

45. Tapia, G.; Elwany, A. A review on process monitoring and control in metal-based additive manufacturing. J. Manuf. Sci. Eng. 2014, 136, 060801. [CrossRef] 
46. Alberts, D.; Schwarze, D.; Witt, G. High speed melt pool \& laser power monitoring for selective laser melting (SLM®). In Proceedings of the 9th International Conference on Photonic Technologies LANE, Fuerth, Germany, 19-22 September 2016.

47. Alberts, D.; Schwarze, D.; Witt, G. In situ melt pool monitoring and the correlation to part density of

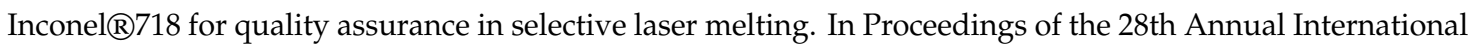
Solid Freeform Fabrication Symposium, Austin, TX,USA, 7-9 August 2017; pp. 1481-1494.

48. Schmid, S. Detektion von Prozessstörungen beim Laserstrahlschmelzen Mittels Online-Prozessüberwachung und Methoden des Maschinellen Lernens. Master Thesis, Technical University of Munich, Munich, Germany, 2018.

49. Genzel, C.; Denks, I.A.; Gibmeier, J.; Klaus, M.; Wagener, G. The materials science synchrotron beamline EDDI for energy-dispersive diffraction analysis. Nuc. Instr. Met. Phys. Res. Sec. 2007, 578, 23-33. [CrossRef]

50. ISO 25178-2:2012. Geometrical Product Specifications (GPS)-Surface Texture: Areal-Part 2: Terms, Definitions and Surface Texture Parameters; Beuth Verlag: Berlin, Germany, 2012.

51. Giessen, B.C.; Ordon, G.E. New high-speed technique based on X-ray spectrography. Science 1968, 159, 973-975. [CrossRef] [PubMed]

52. Hauk, V. Chap. 2.06-Definition of macro- and microstresses and their separation. In Structural and Residual Stress Analysis by Nondestructive Methods; Hauk, V., Ed.; Elsevier Science B.V.: Amsterdam, The Netherlands, 1997; pp. 129-215. [CrossRef]

53. Kasperovich, G.; Haubrich, J.; Gussone, J.; Requena, G. Correlation between porosity and processing parameters in TiAl6V4 produced by selective laser melting. Mat. Des. 2016, 105, 160-170. [CrossRef]

54. Li, Y.; Gu, D. Parametric analysis of thermal behavior during selective laser melting additive manufacturing of aluminum alloy powder. Mat. Des. 2014, 63, 856-867. [CrossRef]

55. Zhuang, J.-R.; Lee, Y.-T.; Hsieh, W.-H.; Yang, A.-S. Determination of melt pool dimensions using DOE-FEM and RSM with process window during SLM of Ti6Al4V powder. Optics Laser Techn. 2018, 103, 59-76. [CrossRef]

56. Udroiu, R.; Braga, I.C.; Nedelcu, A. Evaluating the quality surface performance of additive manufacturing systems: Methodology and a material jetting case study. Materials 2019, 12, 995. [CrossRef] [PubMed]

(C) 2020 by the authors. Licensee MDPI, Basel, Switzerland. This article is an open access article distributed under the terms and conditions of the Creative Commons Attribution (CC BY) license (http://creativecommons.org/licenses/by/4.0/). 